\title{
Structural studies of thyroid peroxidase show the monomer interacting with autoantibodies in
}

\section{Affiliations}

8 1Department of Biochemistry and Molecular Biology, Biomedicine Discovery Institute, Monash

9 University, Clayton, Victoria 3800, Australia

10 2Institute of Biochemistry and Biophysics, Polish Academy of Sciences, Warsaw, Poland

11 3Department of Biochemistry and Molecular Biology, Centre of Postgraduate Medical Education,

12 Warsaw, Poland

134 4Emeritus, King's College London School of, London, United Kingdom.

*To whom correspondence and reprint requests should be addressed:

\section{Ashley M. Buckle}

17 The Department of Biochemistry and Molecular Biology, Biomedicine Discovery Institute, Monash

18 University, Clayton, Vic 3800 Australia; Tel: +613 99029313; Email: ashley.buckle@monash.edu

Keywords: Autoimmune thyroid disease, thyroid peroxidase, autoantigen, electron microscopy

Disclosure Summary: The authors have nothing to disclose. 


\section{Abstract}

Thyroid peroxidase (TPO) is a critical membrane-bound enzyme involved in the biosynthesis of multiple thyroid hormones, and is a major autoantigen in autoimmune thyroid diseases such as Graves' disease and Hashimoto's thyroiditis. Here we report the biophysical and structural characterisation of two novel TPO constructs containing only the ectodomain of TPO and lacking the

30 propeptide. Both constructs were enzymatically active and able to bind the patient-derived TR1.9

31 autoantibody. Analytical ultra-centrifugation data suggests that TPO can exist as both a monomer

32 and a dimer. Combined with negative stain electron microscopy and molecular dynamics 33 simulations, these data show that TR1.9 autoantibody preferentially binds the TPO monomer, 34 revealing conformational changes that bring together previously disparate residues into a 35 continuous epitope. In addition to providing plausible structural models of a TPO-autoantibody 36 complex, this study provides validated TPO constructs that will facilitate further characterization, 37 and advances our understanding of the structural, functional and antigenic characteristics of TPO, a molecule behind some of the most common autoimmune diseases. 
Introduction

Thyroid Peroxidase (TPO) is an enzyme in the thyroid gland responsible for oxidising iodide ions

to form iodine (mediated by hydrogen peroxide), which can then be incorporated into the key

thyroid hormones triiodothyronine $\left(T_{3}\right)$ and thyroxine $\left(T_{4}\right)$ 1. These hormones are critical in the

regulation of metabolism. TPO is of clinical significance, as it is a target of autoantibodies and

autoreactive $T$ cells in autoimmune thyroid diseases (AITD) such as destructive thyroiditis

(Hashimoto's disease) and hyperthyroidism (Grave's disease) 2,3. AITDs are some of the most

common autoimmune diseases in the developed world, with Hashimoto's disease being a strong risk

factor for thyroid cancer 4. TPO is suspected to be involved in the pathogenesis of Hashimoto's

thyroiditis (prevalence 300-2980 cases per 100,000 in the Western world), leading to thyrocyte destruction via CD8+ T-cell infiltration resulting in hypothyroidism 1,3,5. This incidence rate can be compared to other autoimmune diseases - for example type 1 diabetes, which has an incidence in the developed world of $310-570$ cases per 100,000 patients - demonstrating the immense disease burden caused by AITDs 5. The pathogeneses that underlies these autoimmune diseases is complex, however the lack of any tertiary or quaternary structure of TPO complicates matters. The absence of a structure in which to understand binding of anti-TPO antibodies, which are prevalent almost ubiquitously (>95\%) in cases of destructive thyroiditis, complicates the understanding of the pathogenesis and nature of the disease. The precise mechanism by which these antibodies cause damage is uncertain 2. Additionally, in some cases AITDs can occur without these autoantibodies being present, and transplacental passage of anti-TPO antibodies does not necessarily cause thyroid damage in the offspring $3,6,7$. Despite this, transplacental passage of these autoantibodies can potentially have cognitive effects on the child. In addition, antibodies to thyroglobulin ( $\mathrm{Tg}$ ) and thyroid stimulating hormone receptor have been identified in both conditions, indicating that there may be multiple antigens in AITD pathogenesis 2. 
(MPO), eosinophil peroxidase (EPO) and lactoperoxidase (LPO). This family is characterised by high sequence identity and their iron containing heme groups required for their peroxidase activity. Additionally, a conserved calcium binding site (TPO: His261) is observed across the family, which is critical for coordination of the heme group into the active site 8. Proteins within this family exist as both monomers (EPO, LPO) and well as dimers (MPO) in vivo 1. Additionally, TPO is extensively posttranslationally modified (PTM) via N- and O-glycans, another feature of the family. TPO however is the only member of this family which is a transmembrane protein 9,10. TPO is a 933 amino acid long, $107 \mathrm{kDa}$ transmembrane glycoprotein made up of several domains: a heme-containing and catalytically active myeloperoxidase (MPO)-like domain, a complement control protein (CCP)-like domain, an epidermal growth factor (EGF)-like domain, a transmembrane domain and an intracellular domain (Figure 1) 1,11. The known homologues of TPO, including LPO and MPO, have 48\% and $47 \%$ sequence similarity respectively (in relation to the MPO-like domain within TPO), and both LPO and MPO are crystallisable with known structures 12,13. However, no known structure of TPO exists despite previously reported crystals, due to poor diffraction 14,15. The MPO-like domain contains the active site with the catalytically important heme group that is covalently attached to Glu408 and Asp260, as well as His261 necessary for calcium binding 1 . This domain is highly alpha helical. Both the CCP and EGF-like domains are small domains that are both $\beta$-strand rich 8.

To date, the question of whether TPO exists as a monomer or as a dimer remains open. MPO functions as a dimer, and the conserved cysteine at residue 296 in TPO's MPO-like domain would suggest a likely site of dimerisation. Despite this, no evidence revealing where in the cell TPO dimers are formed is available, however it has been shown that MPO dimerises after leaving the ER 10,16. In contrast, it has been shown that MPO can exist and function as a monomer in vivo despite usually presenting as a dimer 16 . In the absence of structural characterisation, we previously modelled TPO as homodimer bound by the conserved cysteine residue Cys296 8. Due to the location of this linkage, symmetry restraints and evidence from the primary sequence, it was proposed that the dimer can be modelled in two plausible ways - with the active site of the MPO-like domain facing toward (cis) 
or away (trans) from the thyrocyte membrane.

Epitope mapping studies using patient derived autoantibodies against TPO have revealed a pattern of antibody recognition sites in two distinct regions, named immunodominant region A (IDR-

A) and immunodominant region B (IDR-B) (Table S1) 10. Mapping these regions onto models of a TPO dimer showed that the MPO-like domain was the dominant locale of both IDRs 8. IDR-A was not closely clustered on either the cis or trans model, and the epitopes in some cases were too sparse to be engaged by a single antibody. This would suggest that TPO may exhibit flexibility allowing these

101 regions to coalesce into one discrete epitope. In IDR-B, the epitopes cluster close to the MPO-like

102 domain dimer interface in both cis and trans models, burying parts of the epitope in this interface.

103 As such, the question of whether TPO exists as a monomer or dimer is central to understanding its 104 autoantigenicity 1,8. Thus, probing the structural characteristics of TPO may provide key insights into 105 the molecular basis of autoimmune disease.

106 In order to understand whether TPO exists as a monomer or dimer and to provide more insights

107 into its structure, here we report a structural, functional and biophysical characterization of two TPO constructs; $\triangle$ proTPOe-8His and $\triangle$ proTPOe-GCN4, the latter with a leucine zipper dimerisation motif engineered to stabilise the dimer form. 


\section{Materials and Methods}

117 An inverse PCR reaction was performed on pcDNA/FRT5/AproTPOe/8His plasmid 17 using the

118 following primers: forward 5'-TGATAGTCTAGAGTCGAC-3' and reverse $5^{\prime}$ -

119 GTGGTGGTGGTGGTGGTGGTGGTGAGTCGCCCGAGGGAGCCT-3' to introduce a C-terminal 8x His tag

120 into the cDNA of the clone. A Dpn/ digestion was performed on the PCR products followed by a blunt

121 end ligation. Ligated products were transformed into chemically competent DH5 $\alpha$ cells. Successful

122 colonies were screened and sequenced on both strands.

Construction of $\triangle$ proTPOe containing the yeast GCN4 dimerisation motif

The gene for the yeast GCN4 dimerisation motif was chemically synthesised (GenScript) and subcloned with Notl and BamHI into the pUC57 ampicillin resistant vector containing the C-terminal $\Delta$ proTPOe sequence. The pcDNA5/FRT/ $\mathrm{p}$ roTPOe and pUC57/GCN4 plasmid was simultaneously digested with Notl and BamHI and the final products isolated on a $1 \%$ agarose gel and subjected to gel purification. Cloning of the yeast GCN4 dimerisation motif into the pcDNA5/FRT/ $\Delta$ proTPOe/8His plasmid product was achieved by utilising an internal BamHI restriction site within the $\triangle$ proTPOe protein sequence and a Notl site in the vector. Both plasmid products were digested with BamHI, ligated and then transformed into chemically competent $\mathrm{DH} 5 \alpha$ cells. Successful colonies were screened and sequenced on both strands.

136 EXPI293 cells (ThermoFisher Scientific) were transiently transfected with the $\Delta$ proTPOe-8His and

$137 \Delta$ proTPOe-GCN4 pcDNA5/FRT plasmids respectively. These cells were diluted to $0.5 \times 10_{5}$ cells per 138 millilitre 48 hours prior to transfection with FreeStyle 293 Expression Medium (ThermoFisher 139 Scientific). Plasmid DNA isolated above was added to pre-warmed PBS at a ratio of $1 \mu \mathrm{g} / \mathrm{mL}$ of cell 
bioRxiv preprint doi: https://doi.org/10.1101/2019.12.15.876789; this version posted December 16, 2019. The copyright holder for this preprint (which was not certified by peer review) is the author/funder, who has granted bioRxiv a license to display the preprint in perpetuity. It is made available under aCC-BY-NC-ND 4.0 International license.

140 culture, in addition to polyethylenimine at a rate of $4 \mu \mathrm{g}$ per $1 \mu \mathrm{g}$ of DNA. Cells were counted and

141 adjusted to $1.5 \times 10_{6}$ cells $/ \mathrm{mL}$ which had $>95 \%$ viability for transfection. This buffer was added to the

142 culture to an amount equal to $10 \%$ of the final volume. Glucose concentration was adjusted to 33

$143 \mathrm{mmol} / \mathrm{L}$, and the cells were incubated at $37^{\circ} \mathrm{C}$ with $5 \% \mathrm{CO}_{2}$ for 7 days. Final concentrations of $20 \mu \mathrm{M}$

144 hematin and $10 \mu \mathrm{M}$ hydrogen peroxide were added to the culture twice during the course of 145 expression. remove any cell debris. $\triangle$ proTPOe was purified from conditioned media via immobilised metal

150 affinity chromatography, using a nickel-nitrilotriacetic acid (Ni-NTA, Qiagen) sepharose. Once bound, 151 the resin was washed with wash buffer (PBST-0.05\% Tween 20, $10 \mathrm{mM}$ imidazole) to remove loosely 152 and non-specifically bound proteins. $\triangle$ proTPOe constructs were eluted with elution buffer (PBST$0.05 \%, 240 \mathrm{mM}$ imidazole), pooled and concentrated. As a final polishing step, $\Delta$ proTPOe was further purified by a HiLoad Superdex S200 16/60 column (GE Healthcare) using gel filtration buffer (1x PBS pH 7.4, 0.01\% Tween 20). $\Delta$ proTPOe eluted as a single symmetric peak. Protein purity was analysed by SDS-PAGE and Western blotting.

159 The TR1.9 Fab sequence contained within a pBP101 plasmid was transformed, expressed and 160 purified as previously published 18.

163 An ELISA was performed to determine whether TR1.9 Fab would bind to both TPO constructs, $164 \Delta$ proTPOe-8His and $\triangle$ proTPOe-GCN4. The experiment included a number of controls (IgG, positive control, conserpin 19, negative control, as well as PBS blanks). 
bioRxiv preprint doi: https://doi.org/10.1101/2019.12.15.876789; this version posted December 16, 2019. The copyright holder for this preprint (which was not certified by peer review) is the author/funder, who has granted bioRxiv a license to display the preprint in perpetuity. It is made available under aCC-BY-NC-ND 4.0 International license.

A 96-well polystyrene ELISA plate (Corning) was coated with diluted antigen in PBS (either TPO or control at $10 \mu \mathrm{g} / \mathrm{mL}$ ) and incubated at room temperature for 4 hours. The plates were then washed with PBST-0.05 (1x PBS pH 7.4, 0.05\% Tween 20). four times and then blocked with $5 \%$ skim milk in PBST-0.05, pH 7.4 overnight at $4{ }^{\circ} \mathrm{C}$. The plates were then once again washed four times with PBSTdilution in PBST-0.05, and then incubated at room temperature for 30 minutes. The plates were once again washed under the same conditions as stated earlier, before 1:2000 dilutions of the secondary antibodies in PBST-0.05 (anti-human IgG conjugated with horseradish peroxidase (HRP), or anti-His, ThermoFlsher Scientific) were added, followed by another 30-minute incubation at room temperature. After a final wash, detection was performed using a 1-Step Ultra-TMB $\left(3,3^{\prime}, 5,5^{\prime}\right.$ tetramethylbenzidine) ELISA solution (ThermoFisher Scientific). A final addition of an equal amount of $100 \%$ acetic acid after one hour acted as a stop solution. The absorbance readings were then measured via an endpoint protocol on a BioRad 96-well plate reader, at a wavelength of $450 \mathrm{~nm}$.

Analysis of $\triangle$ proTPOe-TR1.9 Fab complex using size-exclusion chromatography minutes before injection onto a Superdex S200 16/60 size-exclusion column (GE Healthcare). The sample was run at $1.0 \mathrm{~mL} / \mathrm{min}$ and eluted in $1.5 \mathrm{~mL}$ fractions, before being analysed by SDS-PAGE.

\section{Western blot analysis}

187 Following SDS-PAGE analysis, the proteins on the gel were transferred to a PVDF membrane at 188 100V for one hour. The membrane was then blocked in 5\% skim milk in PBST-0.05 at room 189 temperature for one hour with shaking. Constructs containing a His tag were detected by a single 190 step horse radish peroxidase (HRP)-conjugated anti-His antibody produced in mouse (ThermoFisher 191 Scientific) at a 1:1000 dilution. TR1.9 Fab was detected by a HRP-conjugated anti-human IgG (Fab 
bioRxiv preprint doi: https://doi.org/10.1101/2019.12.15.876789; this version posted December 16, 2019. The copyright holder for this preprint (which was not certified by peer review) is the author/funder, who has granted bioRxiv a license to display the preprint in perpetuity. It is made available under aCC-BY-NC-ND 4.0 International license.

specific) at the same dilution for one hour. Both were washed with TBS-T four times before application of an electrochemiluminescence (ECL) solution (GE Healthcare) and visualised by X-ray photographic film (FujiFilm) at various exposure times.

197 Samples of $\triangle$ proTPOe-GCN4 were run on an SDS-PAGE gel with fresh tricine running buffer and spectrometric analysis using LC-MS/MS was performed at the Monash Biomedical Proteomics Facility. Peptide fragments were compared against a reference $\triangle$ proTPOe-GCN4 sequence.

\section{Guaiacol activity assay}

TPO can also oxidise the compound guaiacol, which remains colourless in solution, to

204 tetraguaiacol, which appears orange. This characteristic can be exploited by spectroscopic analysis to record the enzymatic activity of TPO. This reaction was undertaken in 96-well plates, with each reaction containing $0.1 \mathrm{mg} / \mathrm{mL}$ TPO sample, $1 \mathrm{mM}$ hydrogen peroxide, $33 \mathrm{mM}$ guaiacol and TPO. density over time.

213 The successful incorporation of an iron containing heme group in proteins can be detected by

214 what is known as a Soret peak. $\triangle$ proTPOe-8His and $\triangle$ proTPOe-GCN4 at a concentration of 0.5

$215 \mathrm{mg} / \mathrm{mL}$ in $1 \times \mathrm{PBS} \mathrm{pH} 7.4$ were placed in a cuvette and a fluorescence spectrum was obtained, with an

216 incident wavelength of $330 \mathrm{~nm}$. A distinctive peak at $385 \mathrm{~nm}$ is a Soret peak and is distinctive of hemoproteins. This absorbance spectrum was obtained on a HoribaJobinYvon FluoroMax4 
spectrophotometer.

TPO constructs at a final concentration of $0.3 \mathrm{mg} / \mathrm{mL}$ were placed in different buffer conditions

(NanoTemper).

\section{Binding affinity measurements}

Bio-layer interferometry experimental data was collected via a BLItz instrument (FortéBio). NiNTA biosensors were equilibrated overnight in 1x PBS, $0.01 \%$ Tween $20,1 \% \mathrm{BSA}, \mathrm{pH} 7.4$ at $4{ }^{\circ} \mathrm{C}$ before use. This assay consisted of five steps: initial baseline (30 s), protein loading (150 s), baseline

230 (30 s), association (240 s) and dissociation (480 s). All steps occurred using the same buffer composition listed above. $\Delta$ proTPOe- $8 \mathrm{His}$ was loaded onto the biosensors during the loading phase at a concentration of $50 \mu \mathrm{g} / \mathrm{mL}$ as per the manufacturer's specifications, with a loading signal of approximately $1 \mathrm{~nm}$. TR1.9 Fab was incubated with the biosensors at concentrations of $0,50,100$, and $500 \mathrm{nM}$ during the association phase. A blank control reading was used as a baseline during data processing. Using the BLItz Pro version 1.2.1.3 software, the dissociation constant $K_{D}(n M)$, and the rate constants $k_{a}(1 / M s)$ and $k_{d}(1 / s)$ were calculated using a 1:1 binding model with global fitting. Curves were adjusted within the BLItz Pro software to match at the start of both association and dissociation in order to adjust for changes in conditions between steps. $R_{2}$ values for the calculated fit were reported as 0.97 .

242 AUC can be used to observe the oligomerisation status of proteins, as well as analyse complex 
bioRxiv preprint doi: https://doi.org/10.1101/2019.12.15.876789; this version posted December 16, 2019. The copyright holder for this preprint (which was not certified by peer review) is the author/funder, who has granted bioRxiv a license to display the preprint in perpetuity. It is made available under aCC-BY-NC-ND 4.0 International license.

244 ultra-centrifuged in a BeckmanCoulter Analytical Centrifuge using a double sector cell with quartz

245 windows in 4-hole An60-Ti rotors. The wavelengths for further analysis were selected by an initial scan at 3000 RPM at room temperature to select the best radial settings. For the sedimentation velocity experiment, $420 \mu \mathrm{L}$ of sample and $400 \mu \mathrm{L}$ of buffer (1x PBS pH 7.4) were placed in each cell and the experiment was run with the radial settings discussed earlier at 40,000 RPM. 500 scans were performed with a rate of 15 scans per minute. Information about buffer viscosity, density and partial volume were determined by the software SEDNTERP. A c(s) sedimentation distribution model was

https://sedfitsedphat.nibib.nih.gov/software/default.aspx.

Negative stain electron microscopy (EM) analysis

A TPO-Fab complex was formed by addition of a 2x molar excess of TR1.9 Fab to freshly purified $\Delta$ proTPOe-8His. This was incubated on ice for $30 \mathrm{~min}$ before separation using an analytical S200 10/300 column in $1 \times$ PBS pH 7.4 (GE Healthcare). $10 \mu \mathrm{L}$ of $\Delta$ proTPOe-8His alone and in complex with TR1.9 Fab at $0.05 \mathrm{mg} / \mathrm{mL}$ were pipetted onto freshly glow discharged carbon grids and stained with

Parametrisation and molecular dynamics (MD) simulations of TPO constructs were performed on in-house hardware using NVIDIA 1080 Ti Pascal GPUs.

269 Starting structures for cis and trans variants of $\triangle$ proTPOe were derived from the models 
bioRxiv preprint doi: https://doi.org/10.1101/2019.12.15.876789; this version posted December 16, 2019. The copyright holder for this preprint (which was not certified by peer review) is the author/funder, who has granted bioRxiv a license to display the preprint in perpetuity. It is made available under aCC-BY-NC-ND 4.0 International license.

presented in Le and co-workers 8. An extended variant of $\Delta$ proTPOe was developed which did not bias the orientation of the CCP-like and EGF-like in relation to the MPO-like domain. Additionally, each structure had separate runs with unrestrained, as well as positionally restrained IDR residues. These residues were weakly constrained with harmonic position restrains of $2 \mathrm{kcal} \AA_{2}$ mol-1. These proteins contained protonation states appropriate for $\mathrm{pH} 7.0$ (as determined by PROPKA) and were inserted in a rectangular box with a border with a minimum of $12 \AA 21,22$. They were then explicitly solvated with TIP3P water, sodium counter-ions were added and then the system was parameterised using the AMBER ff99SB forcefield 23-26. After 10000 steps of energy minimisation, an equilibration stage was performed. The temperature was raised from $0 \mathrm{~K}$ to $300 \mathrm{~K}$ with a constant volume and a $10 \mathrm{~K}$ ramp over $1 \mathrm{~ns}$, with Langevin temperature coupling relaxation times of $0.5 \mathrm{ps}$. After the target temperature was achieved, the pressure was equilibrated to $1 \mathrm{~atm}$ using the Berendsen algorithm over 0.5 ps 27. The MD simulations used periodic boundary conditions and a time step of $2 \mathrm{fs}$, with temperature maintained at $300 \mathrm{~K}$ using the Langevin thermostat and pressure maintained at $1 \mathrm{~atm}$ using the Berendsen method as described above. All MD simulations were run in triplicate, with the same starting structure but with altered starting velocities following the equilibration and parametrisation steps. Each run extended for 400 ns using NAMD 2.928.

\section{MD analysis}

Manipulation and analysis of the simulations were performed using VMD 1.9.3, MDTraj and custom scripts 29,30 . Models of $\Delta$ proTPOe were analysed for root mean square deviation (RMSD), with the RMSD of backbone heavy atoms in relation to the initial structure calculated for every 0.1 ns of simulation after calculating a least-square fit. Output structures for further analysis were selected from a plateau in the RMSD calculation, whereby the structure adopted a stable state. Distance between selected IDR residues in each frame was also calculated using VMD and custom scripts. RMSD is given as an average value per residue per $0.1 \mathrm{~ns}$ of simulation time. All structural representations were prepared using PyMOL 2.3.2. 
bioRxiv preprint doi: https://doi.org/10.1101/2019.12.15.876789; this version posted December 16, 2019. The copyright holder for this

preprint (which was not certified by peer review) is the author/funder, who has granted bioRxiv a license to display the preprint in perpetuity. It is made available under aCC-BY-NC-ND 4.0 International license. 
Results

300

\section{Expression and Purification of TPO constructs}

TPO's domain structure, the engineered constructs and structural models are shown in Figure 1.

The $\Delta$ proTPOe-8His construct lacks a propeptide domain, which has previously been shown to not

310 is consistent with that of a $110 \mathrm{kDa}$ according to our calibration (Figure $2 \mathrm{C}$ ). There appears to be no

311 other high molecular weight species on the chromatogram. Despite this, the fractions making up this

312 peak when analysed via reducing SDS-PAGE (Figure 2A) demonstrate a number of minor species,

which may be due the heterogeneous nature of the glycosylation of TPO or protein degradation from proteases released from cells during the 7-day expression cycle.

In an attempt to favour TPO dimerisation we engineered a GCN4 leucine zipper dimerisation confirmed the presence of intact $\Delta$ proTPOe-GCN4 ( 110 kDa) (Figure S2). Despite the quality of our

319 preparations, TPO suffered from a shorter shelf life and often appeared to degrade into a $75 \mathrm{kDa}$ component according to SDS-PAGE. This fragment was analysed by mass spectrometry and was

321 identified as a truncated TPO (Figure S3). Enzymatic activity of the constructs was validated by spectroscopic analysis, measuring both proper heme incorporation as well as function via the guaiacol activity assay (Figure 3 ). Whereas $\Delta$ proTPOe-8His is enzymatically active, activity could not 
bioRxiv preprint doi: https://doi.org/10.1101/2019.12.15.876789; this version posted December 16, 2019. The copyright holder for this preprint (which was not certified by peer review) is the author/funder, who has granted bioRxiv a license to display the preprint in perpetuity. It is made available under aCC-BY-NC-ND 4.0 International license.

$\Delta$ proTPOe-8His shows statistically significant activity, suggesting that this protein is likely enzymatically active and correctly folded (Figure 3B). Since the thermal stability of TPO has not been reported to date, we measured the stability of the $\Delta$ proTPOe-8His construct using thermal unfolding and monitoring intrinsic tryptophan fluorescence in several buffer conditions. The midpoint of unfolding $(\mathrm{Tm})$ of $\Delta$ proTPOe-8His reached a maximum of $55.2{ }^{\circ} \mathrm{C}$ at $\mathrm{pH} 7.0$ (Table S2). We next showed that TR1.9 Fab binding completely inhibits the catalytic activity of TPO (Figure 3C).

\section{Assessment of Oligomerisation State of TPO Constructs}

Chromatographic analysis suggests that the TPO constructs behave as monomers, but we suspected that based upon previous work that the TPO molecule is elongated and relatively flexible, and thus we are unable to unambiguously differentiate between monomers and dimers 1,8. From the size-exclusion chromatography data, it is possible that the monomer and dimer of TPO are not separated if they have the same or similar Stokes radii $\left(R_{s}\right)$, which may be possible given their symmetry. We therefore next used analytical ultracentrifugation and sedimentation velocity experiments to provide equilibrium information about TPO's shape, size and oligomeric state. For $\triangle$ proTPOe-GCN4, two species could be detected, having a standardised weight-average sedimentation coefficient of 3.6 and 5.2 (Figure 4A). The molecular weights reported by $c(M)$ analysis (not shown) in each case was $114 \mathrm{kDa}$ and $201 \mathrm{kDa}$ respectively, with a frictional ratio of 2.36. These molecular weights are consistent with a monomer ( $110 \mathrm{kDa})$ and a dimer $(\sim 220 \mathrm{kDa})$ species. The relative abundance of each of the two species was analysed by SEDFIT (using area under the curve), with a monomer:dimer ratio of approximately $1.33: 1$, indicating the monomer is more abundant. The frictional ratio of 2.36 suggest a non-spherical, elongated shape, consistent with our previous modelling (a frictional ratio of 1 would suggest a perfect sphere) 8. For the $\Delta$ proTPOe-8His construct (Figure 4B), two species of standardised weight-average sedimentation coefficient of 3.5 and 5.0 were detected, which were similar to the $\triangle$ proTPOe-GCN4 construct. The monomer:dimer ratio appears in this case to be closer to 1:1 in terms of distribution. This would 
bioRxiv preprint doi: https://doi.org/10.1101/2019.12.15.876789; this version posted December 16, 2019. The copyright holder for this preprint (which was not certified by peer review) is the author/funder, who has granted bioRxiv a license to display the preprint in perpetuity. It is made available under aCC-BY-NC-ND 4.0 International license.

351

352

353

354

355

356

357

358

359

360

361

362

363

364

365

366

367

368

369

370

371

372

373

374

375

376

indicate that both constructs exist as monomeric and dimeric forms in solution. Calculated Stokes radii are listed in Table S3.

\section{Characterisation of a human TPO-autoantibody complex}

In order to gain insight into the nature of the interaction between TPO and the patient-derived TR1.9 autoantibody, we expressed the Fab portion of TR1.9 as previously described 18. TR1.9 Fab was shown to bind both $\triangle$ proTPOe-8His and $\triangle$ proTPOe-GCN4 using ELISA (Figure 5). It is apparent from the size-exclusion chromatogram that Fab binds to full-length $\triangle$ proTPOe-8His (Figure $5 \mathrm{~A}$ ). There was only a minor peak shift with no appearance of any large species on the chromatogram (dimeric TPO with two Fabs would exceed $320 \mathrm{kDa}$ ), which would suggest a stoichiometric monomeric TPO-Fab complex. We also calculated the Stokes radii of the various TPO constructs with and without Fab using analytical size-exclusion chromatography as well as AUC (Table S3). Bio-layer interferometry indicated that $\Delta$ proTPOe-8His binds TR1.9 Fab with an affinity of $20 \mathrm{nM}$ (Figure S4). Taken together, this data confirms the antigenic quality of our constructs.

\section{Analytical Ultra-centrifugation of the $\Delta$ proTPOe-GCN4-TR1.9 Fab Complex}

We next used analytical ultra-centrifugation to investigate the association between TR1.9 Fab and $\triangle$ proTPOe-GCN4, as well as the effect of TR1.9 Fab binding on the equilibrium of monomer and dimer TPO species. The sedimentation coefficient for TR1.9 Fab alone was determined as $\mathrm{sw}(20, \mathrm{w})=$ 2.6S. AUC analysis of an equimolar mixture of TR1.9 Fab and $\triangle$ proTPOe-GCN4 shows two peaks (Figure $5 \mathrm{C}$ ). The lack of a peak at $2.6 \mathrm{~S}$ suggests that none, or very little of the Fab, remained uncomplexed. Therefore, the two remaining peaks are most likely the TPO monomer/dimer peaks as observed in the previous experiment (Figure 4A). The observed shift in their standardised weightaverage sedimentation coefficients (4.1S, $6.6 \mathrm{~S}$, respectively) suggest a change in their shape and mass, indicating Fab binding to both monomer and dimer $\triangle$ proTPOe-GCN4. The frictional ratio has also changed to 1.77 (from 2.36 with $\triangle$ proTPOe-GCN4 alone), indicating that TPO has taken a more 
bioRxiv preprint doi: https://doi.org/10.1101/2019.12.15.876789; this version posted December 16, 2019. The copyright holder for this preprint (which was not certified by peer review) is the author/funder, who has granted bioRxiv a license to display the preprint in perpetuity. It is made available under aCC-BY-NC-ND 4.0 International license.

spherical shape upon TR1.9 Fab binding. Importantly, the ratio of monomer and dimer has shifted to approximately 2:1. This indicates that TR1.9 Fab preferentially binds the TPO monomer, thus perturbing the monomer:dimer equilibrium.

\section{Analytical Ultracentrifugation of $\Delta$ proTPOe-8His with TR1.9 Fab}

The same sedimentation velocity experiments were undertaken with $\Delta$ proTPOe- $8 \mathrm{His}$ in the presence of TR1.9 Fab, with the Fab in 2-fold excess of TPO. Two distinct species were observed (Figure 5D), with a standardised weight-average sedimentation coefficient of 2.8 and 3.9. This is largely consistent with the Fab alone (2.6S) and $\Delta$ proTPOe-GCN4 monomer plus TR1.9 Fab (4.1S) data obtained previously with the alternate construct. Interestingly, in this case there appears to be no other large species, indicating that the binding of Fab has pushed the monomer:dimer equilibrium such that all $\triangle$ proTPOe-8His exists exclusively in its monomeric form. AUC further shows that TR1.9 Fab can successfully bind both TPO constructs.

The monomeric $\Delta$ proTPOe-8His with Fab has a frictional ratio of 1.90 and a Stokes radius of 57.4, similar to that of the monomeric form of $\triangle$ proTPOe-GCN4 bound with Fab (Table S3). Taken together, these data indicate that TPO adopts an elongated, non-spherical structure, consistent with our previous model 8 . However, a decrease in both the frictional ratio and Stokes radius when bound with TR1.9 Fab suggests that $\Delta$ proTPOe-8His adopts a more compact, globular shape upon antibody binding.

\section{Molecular Dynamics Simulations Reveal Monomer Conformations Compatible with Antibody}

\section{Binding}

Given the structural changes indicated by AUC data, we next used molecular dynamics simulations to explore the structure of TPO monomers in molecular detail. Our previous modelling analysis of epitope mapping data suggest that some residues in IDR-A are too far away to be engaged by a single autoantibody 8 . One such autoantibody, T13, is reported to bind H353-Y363, 
403 P377-R386, K713-S720 and Y766-Q775 31-34. The average maximum dimension of an epitope-

404 containing surface is reported at $28 \AA$ (s.d. of $8 \AA$ ) 35. In contrast, in our previous models of TPO

405 residues implicated in antibody binding are more disperse, with some residue pairs separated by

406 more than $70 \AA$ 8. This discrepancy suggests that TPO may undergo significant conformational

407 change upon antibody binding, such that epitope residues are brought into closer proximity,

408 consistent with our AUC analysis. To explore this hypothesis, we performed molecular dynamics

409 simulations of a $\triangle$ proTPOe monomer in three starting configurations: the cis and trans monomer as

410 generated previously 8, and an extended conformation in which the CCP-like and EGF-like domains of

411 TPO extend out from the MPO-like domain without any bias in its orientation.

412 After approximately 250 ns of MD simulation time, the CCP-like and EGF-like domains of the cis

413 model (containing the epitope Y766-Q775) move towards the MPO-like domain, such that this

414 epitope coalesces around the T13 epitope residues H353-Y363 and R377-R386 (Figures 7, 8 \& S6A).

415 As a result, the average residue separation within the epitope decreases from 56 to $40 \AA$, reaching

$41621 \AA$ at some points in the simulation. This distance is such that it could reasonably be engaged by a

417 single autoantibody via a continuous epitope, which may suggest a mechanism by which

418 autoantibodies could engage multiple sites on TPO that in previous modelling may appear distant.

419 The trans model of TPO behaved in a similar manner during simulation, decreasing its maximum

420 dimension from 100 to $82 \AA$. In contrast however, the CCP-like and EGF-like domains (again

421 containing the same epitope) tended to coalesce around the reported T13 epitope residues K713-

422 S720 on the MPO-like domain, which is also close to R225 and D707 epitope residues (Figures 7, 8,

423 S5 \& S6C). Again, the distance between Y766-Q775 and K713-S720 in the trans model prior to

424 simulation is $51 \AA$, but approached $26 \AA$ during simulation. For the extended model the maximum

425 dimension reduced from $130 \AA$ to $83 \AA$ during the simulation. However, the CCP-like and EGF-like

426 domains condensed in a less homogeneous manner compared to the cis and trans models, such that

427 it was able to adopt multiple conformations relative to the MPO-like domain. Despite this, it is able

428 to stably adopt conformations that result in all four published epitopes for the T13 autoantibody 
bioRxiv preprint doi: https://doi.org/10.1101/2019.12.15.876789; this version posted December 16, 2019. The copyright holder for this preprint (which was not certified by peer review) is the author/funder, who has granted bioRxiv a license to display the preprint in perpetuity. It is made available under aCC-BY-NC-ND 4.0 International license.

colocalising to form a continuous epitope such that they could all be plausibly engaged by a single autoantibody (Figures 7C \& S6B). One such conformation selected from a stable state provided by our MD simulation suggest that all residues involved in these four epitopes are no more than $43 \AA$ away from all other residues in the set of 39 residues previously implicated in the T13 epitope (Figures $8 \mathrm{C} \& \mathrm{S6B}$ ). Taken together, these observations may suggest a mechanism not only by which TPO can alter its conformation to take a more compact and globular structure, but potentially explain how disparate residues involved in the IDRs may compact to form a discrete, continuous epitope.

\section{Analysis of TPO Structure Using Negative Stain Electron Microscopy}

We next investigated the structure of the $\Delta$ proTPOe-8His construct in complex with TR1.9 Fab using negative stain electron microscopy. The most homogenous population of the TPO-Fab complex was selected using size-exclusion chromatography (Figure 5). The representative 2D class averages show a globular compact protein complex and initial 3D reconstruction stalled at a resolution of $\sim 20$

$\AA ̊$ (Figure 8). Although this limitation in resolution means that we cannot unambiguously determine the structure of a TPO-Fab complex, we can however rule out certain configurations. Docking of various models of Fab-bound monomeric and dimeric TPO into the EM envelope suggests that various configurations are feasible. Visual inspection suggests that $\triangle$ proTPOe adopts a relatively compact, rather than extended conformation, consistent with our MD analysis. For further modelling we therefore proceeded using the aforementioned compact conformations resulting from MD simulations for further analysis.

First, we sought to determine if fitting might provide information germane to the oligomerisation state of TPO. For simplicity, only the trans arrangements of $\triangle$ proTPOe will be presented here. There

452 is sufficient space in the EM envelope for either a monomer or dimer of TPO, or a monomer of TPO 453 bound to Fab. There is insufficient space however, for a dimer with two bound Fabs, and so this possibility was rejected. A Fab molecule was fitted to the envelope with the complementarity 
bioRxiv preprint doi: https://doi.org/10.1101/2019.12.15.876789; this version posted December 16, 2019. The copyright holder for this preprint (which was not certified by peer review) is the author/funder, who has granted bioRxiv a license to display the preprint in perpetuity. It is made available under aCC-BY-NC-ND 4.0 International license.

determining regions (CDRs) positioned at a distance of $4 \AA$ from the previously published epitope of TR1.9, K713-S720. This is consistent with studies showing an antibody-epitope distance of $4.5-5 \AA$ 35,36. We also additionally selected a plausible conformation from our MD simulations of trans TPO that showed superior fitting to the EM volume, i.e. a folded or condensed monomer. Calculating the goodness of fit of molecules to the EM envelope as the percentage of molecules contained within the envelope, the trans dimer, trans monomer-Fab complex and condensed monomer-Fab complex contained 54, 53 and 58 percent of molecules within the volume, respectively (Figure 9). This would indicate that the condensed TPO monomer suggested by the MD simulations is the most likely approximation to the solution conformation, at least in the presence of Fab. Fitting the Fab in sequentially with TPO, i.e. not biasing the Fab orientation toward the published epitope, the fit improves to $68 \%$. Despite this however, this fit does not place the CDRs facing in a realistic location the CDRs face away from TPO itself. Intrinsic flexibility between the variable and constant domains of a Fab often results in ambiguity in fitting into EM data, with only the variable domains being resolved in EM density 37-39. Accordingly, fitting only the variable domains of the Fab in a TPO monomer-Fab complex within the envelope improves the fit to approximately $73 \%$ (Table S4). analysis indicating we have a high affinity binding interaction between $\triangle$ proTPOe-8His and TR1.9 Fab, it is unlikely that the Fab is not contained with the EM envelope. Unbound monomer or dimers are thus unlikely. Given that AUC analysis suggests that TR1.9 Fab binds to a TPO monomer and

474 adopts a compact shape upon complexation that is consistent with our MD analysis (Figures 5 and 475 6), the EM data suggests strongly that at least in its non-membrane bound form, TR1.9 binds to TPO as a monomer. 
bioRxiv preprint doi: https://doi.org/10.1101/2019.12.15.876789; this version posted December 16, 2019. The copyright holder for this preprint (which was not certified by peer review) is the author/funder, who has granted bioRxiv a license to display the preprint in perpetuity. It is made available under aCC-BY-NC-ND 4.0 International license.

\section{Discussion}

Native TPO can be isolated and purified from tissue, although the availability of human thyroid tissue is a limiting factor in any preparation of TPO and rarely is enough produced for significant structural characterisation 40. Additionally, during maturation TPO is trimmed by proteolytic cleavage within its $\mathrm{N}$-terminal propeptide region 17,41 . This process of proteolysis is at least in some way responsible for the low homogeneity of TPO that is purified from tissue. The $\Delta$ proTPOe-8His and $\Delta$ proTPOe-GCN4 constructs we describe improve the biochemical quality and production yield of recombinant TPO considerably, having similar functional and immunogenic properties to wild-type TPO.

The correct incorporation of the heme porphyrin ring is essential for the nascent protein's exit from the ER and indeed for protein functionality 16 , requiring hydrogen peroxide provided by the dual oxidase (DUOX) family of proteins present in the thyroid follicular cell membrane and are closely associated with TPO 10,42,43. Anticipating that the autocatalytic process of heme incorporation might be reduced during mammalian expression due to a lack of hydrogen peroxide, the media was supplemented with hydrogen peroxide as well as hematin, resulting in enzyme activity for $\Delta$ proTPOe-8His but not $\triangle$ proTPOe-GCN4 10 . Given that we demonstrate that the heme group has been incorporated, one explanation for the absence of enzyme activity for $\triangle$ proTPOe-GCN4 is possible occlusion of the active site as a result of enforced dimerization due to incorporation of the leucine zipper dimerisation motif.

Both $\triangle$ proTPOe-8His and $\triangle$ proTPOe-GCN4 constructs showed an approximately $75 \mathrm{kDa}$ degradation product after the initial purification, which co-eluted with the full-length protein during size-exclusion chromatography. This behavior may be due to instability or altered glycosylation, which could account for upto $25 \%$ of TPO's $110 \mathrm{kDa}$ molecular mass. There are many splice variants of TPO that have been characterised, indicating its complicated biosynthesis and the relevance of our engineered constructs in providing a consistent protein product 40,44. It is now known that there is more than 10 TPO isoforms 10 . Given the importance of glycosylation in the folding and post- 
bioRxiv preprint doi: https://doi.org/10.1101/2019.12.15.876789; this version posted December 16, 2019. The copyright holder for this preprint (which was not certified by peer review) is the author/funder, who has granted bioRxiv a license to display the preprint in perpetuity. It is made available under aCC-BY-NC-ND 4.0 International license.

504 translational trafficking of TPO 945 , it is unlikely that non-post-translationally modified TPO would be

505 exported. A mere $2 \%$ of TPO synthesised by cells reaches the cell surface as most is degraded by

506 proteases or the proteasome due to partial or complete misfolding 45 . It is possible that during the 7-

507 day time course for expression, proteolytic activity, rather than inherent instability may have led to

508 the observed degradation, consistent with our thermal stability data.

509 There exists evidence for both monomeric and dimeric forms of TPO, and no consensus

510 agreement on its physiological oligomerization state $17,46-48$. Bioinformatic analysis of the peroxidase

511 family is consistent with both monomer and dimer. LPO is the most closely related protein to TPO,

512 with $48 \%$ sequence identity between their MPO-like domains, and is functionally monomeric 1. MPO,

513 with $47 \%$ sequence identity with TPO, is an active dimer stabilized by intermolecular disulfide bonds

514 via a conserved Cys296, which is also conserved in TPO 48. As such, the MPO-like domain of TPO has

515 been modelled exclusively upon the MPO homodimer. Given however that much of the epitope

516 mapping data suggests that autoantibodies disproportionately recognise epitopes of the MPO-like

517 domain of TPO, and that to date TPO dimerization has not been investigated in any detail, a greater

518 understanding of its oligomerization state would be a great benefit in understanding its

519 autoantigenicity 49 . Some insights may be gleaned from studies on MPO, given its common ancestry

520 and function with TPO. MPO dimerisation occurs in the secretory pathway during proteolytic

521 processing 16. In TPO biosynthesis, the propeptide is cleaved after exit from the Golgi apparatus and

522 dimerisation is likely to occur prior to reaching the plasma membrane 10 . As such, dimerisation may

523 occur during the secretory pathway as in MPO, although MPO is not localized in the plasma

524 membrane like TPO, providing additional sites at which TPO may dimerise. A small percentage

$525(\sim 10 \%)$ of MPO is secreted as a fully functional monomer with exactly half the enzyme activity

526 compared to the dimer 16 . As such, MPO activity does not require dimerization and the functional

527 advantages of dimerisation are not understood. It is reasonable to hypothesize therefore that TPO is

528 functional in both monomeric and dimeric states.

529 AUC analysis of the $\triangle$ proTPOe-GCN4 construct is consistent with a monomer:dimer equilibrium, 
bioRxiv preprint doi: https://doi.org/10.1101/2019.12.15.876789; this version posted December 16, 2019. The copyright holder for this preprint (which was not certified by peer review) is the author/funder, who has granted bioRxiv a license to display the preprint in perpetuity. It is made available under aCC-BY-NC-ND 4.0 International license.

530 slightly favoring the monomer. TR1.9 Fab binds the monomer preferentially, shifting the equilibrium

531 to 2:1, suggesting a role of the autoantibody in the monomer-dimer interplay. However, since the

532 GCN4 leucine zipper was introduced as a dimerisation motif, any affect on dimerization by Fab-

533 binding must be interpreted with caution. AUC analysis for $\triangle$ proTPOe-8His construct follows similar

534 behavior in that it can exist as both monomer and dimer, with only the monomer binding to TR1.9

535 Fab. Interestingly, whereas the $\Delta$ proTPOe-8His construct was enzymatically active, the $\Delta$ proTPOe-

536 GCN4 construct was not, suggesting that either the dimer interface may occlude the active site of

537 the protein, or that GCN4 interferes with activity via another mechanism. Inspection of epitope

538 mapping data on the cis model of dimeric TPO indicates that several residues that comprise

539 immunodominant regions are buried. Furthermore, the large and diffuse nature of IDR-A and -B

540 determinants in both cis and trans models suggest that significant conformational changes would be

541 necessary to form a continuous epitope compatible with antibody engagement 8 . Some residues

542 may be surface exposed, but the dimer conformation may prevent autoantibody binding due to

543 steric occlusion. In support of this, AUC analysis shows that the TPO-Fab complex undergoes a large

544 conformational change to become more compact, and also that TR1.9 Fab preferentially binds the

545 monomer, thus shifting the monomer:dimer equilibrium.

546 Our EM analysis provides the first ever structural glimpse regarding information about the

547 ectodomain of TPO. Although the EM resolution is limited, it is consistent with our other data,

548 allowing us with high confidence to eliminate a complex between Fab and a TPO dimer.

549 Furthermore, the EM data strongly supports our SEC and AUC analysis showing that $\triangle$ proTPOe-8His

550 is a monomer when bound to TR1.9 Fab. Modelling of TPO has suggested that membrane bound

551 TPO is an elongated molecule with domains outstretched, however our experimental EM and AUC

552 data suggests that at least for the TPO ectodomain, a much more globular and compact space is

553 taken up in solution, especially when bound to its cognate antibody. This experimental data is

554 supported by MD simulations of $\triangle$ proTPOe in its non-membrane bound form, whereby TPO is able

555 to undergo large changes in conformation (Figure S6). Thus, MD simulations, AUC and EM provide 
bioRxiv preprint doi: https://doi.org/10.1101/2019.12.15.876789; this version posted December 16, 2019. The copyright holder for this preprint (which was not certified by peer review) is the author/funder, who has granted bioRxiv a license to display the preprint in perpetuity. It is made available under aCC-BY-NC-ND 4.0 International license.

convincing evidence that TPO is able to coalesce into a more compact, globular structure in solution.

557 Furthermore, MD analysis reveals how the TPO monomer can change shape such that residues

558 implicated in autoantibody binding that are disparate in space can be bought together to form a continuous epitope. However, we cannot from this data suggest definitively that this is the conformation of TPO when bound to T13 autoantibody. Instead, we argue that our data suggest that TPO may be able to change conformation in such a fashion that previously distal epitopes can coalesce into one discrete, continuous epitope. This may explain the previously conflicting epitope mapping data for some autoantibodies in IDR-A and IDR-B that contained residues that were too far

564 from each other to be engaged by the CDRs of a single autoantibody, based on previous modelling.

565 Despite previous attempts to resolve this issue 14,15, a definitive answer, however, awaits a highresolution structure for TPO alone and in complex with cognate autoantibodies.

All of our analysis, including MD, considers TPO in solution. We expect that the conformational, enzymatic and antigenic properties of TPO in solution are different when it is tethered to the membrane in the human thyroid. We speculate that perhaps, in the case of some TPO autoantibodies such as T13 that bind a range of spatially separate residues on TPO, when membrane bound (due to steric constraints of the membrane and other membrane bound components) the conformation required to display a continuous epitopes would be a rare event. Alternatively, this compacted conformation may become available as the result of improper trafficking to the membrane, followed by conformational change in solution. This rare conformation may perhaps be an explanation behind the observation that diseases involving TPO autoantibodies have not only a 576 slow onset, but also explain the evidence suggesting that TPO autoantibody titre detected in patient 577 serum does not always correlate with disease state 50. Perhaps only some TPO would enter this 578 rarer, antigenic configuration, and thus lead to downstream immune effects, whilst correctly 579 trafficked TPO or TPO in a non-antigenic configuration may remain unaffected by these 580 autoantibodies, resulting in patients with anti-TPO antibody titre without appreciable evidence of disease. Our observation that TR1.9 Fab preferentially binds monomeric $\Delta$ proTPOe-8His may 
indicate that the complex (and thus pathology within the patient) appears when cryptic epitopes that are normally hidden are revealed to the immune system upon dissociation of the dimer. Our data shows that the autoantibody TR1.9 inhibits the catalytic activity of TPO constructs produced, either directly via blocking access to the active site, indirectly by favouring a conformational change that occludes the active site, or both. Although a precise understanding awaits high resolution structural analysis, this behavior suggests an intriguing connection between enzyme function and autoantigenicity that has been demonstrated for other autoantigens 51 .

\section{Conclusions} constructs, $\triangle$ proTPOe-8His and $\triangle$ proTPOe-GCN4, representing new reagents with which to study

593 TPO structure, function and antigenicity. Biophysical characterisation using AUC suggests that the

594 TPO ectodomain can exist as both a monomer and a dimer. EM and molecular dynamics analysis shows that the Fab fragment of the patient-derived TR1.9 autoantibody preferentially binds the TPO monomer, and suggests conformational change that consolidates antibody-binding residues into a continuous epitope. Taken together, these data represent the first glimpses of the structural characteristics of TPO, which thus far has resisted structural characterization by any technique. As a whole, our findings advance our understanding of TPO's structure and function, as well as its role as a major autoantigen in autoimmune thyroid diseases.

601

\section{Acknowledgements}

603 TR 1.9 Fab construct was kindly provided by Sandra McLachlan and Basil Rappoport. We would like 604 to thank Dr. David Steer for help with MS analysis.

605 
607 The datasets generated during and/or analyzed during the current study are not publicly available

608 but are available from the corresponding author on reasonable request.

609

\section{References}

611 1. Williams DE, Le SN, Godlewska M, Hoke DE, Buckle AM. Thyroid Peroxidase as an Autoantigen in Hashimoto's Disease: Structure, Function, and Antigenicity. Hormone and metabolic research $=$ Hormon - und Stoffwechselforschung $=$ Hormones et metabolisme . 2018;50(12):908-921.

2. Fröhlich E, Wahl R. Thyroid Autoimmunity: Role of Anti-thyroid Antibodies in Thyroid and Extra-Thyroidal Diseases. Frontiers in immunology. 2017;8:521.

617 3. Godlewska M, Gawel D, Buckle AM, Banga JP. Thyroid Peroxidase Revisited - What's New? Hormone and metabolic research $=$ Hormon und Stoffwechselforschung $=$ Hormones et metabolisme. 2019;51(12):765-769.

4. Silva de Morais N, Stuart J, Guan H, et al. The Impact of Hashimoto Thyroiditis on Thyroid Nodule Cytology and Risk of Thyroid Cancer. Journal of the Endocrine Society. 2019;3(4):791800.

5. Cooper GS, Stroehla BC. The epidemiology of autoimmune diseases. Autoimmunity reviews. 2003;2(3):119-125.

6. Sarkhail P, Mehran L, Askari S, Tahmasebinejad Z, Tohidi M, Azizi F. Maternal Thyroid Function and Autoimmunity in 3 Trimesters of Pregnancy and their Offspring's Thyroid through the placental barrier during pregnancy. PloS one. 2014;9(1):e84647. 
633 9. Godlewska M, Arczewska KD, Rudzinska M, et al. Thyroid peroxidase (TPO) expressed in thyroid and breast tissues shows similar antigenic properties. PloS one. 2017;12(6):e0179066.

10. Godlewska M, Banga PJ. Thyroid peroxidase as a dual active site enzyme: Focus on biosynthesis, hormonogenesis and thyroid disorders of autoimmunity and cancer. Biochimie. 2019;160:34-45.

11. Kimura S, Kotani T, McBride OW, et al. Human thyroid peroxidase: complete cDNA and protein sequence, chromosome mapping, and identification of two alternately spliced

12. Singh AK, Singh $N$, Sinha $M$, et al. Binding modes of aromatic ligands to mammalian heme mRNAs. Proceedings of the National Academy of Sciences of the United States of America. peroxidases with associated functional implications: crystal structures of lactoperoxidase complexes with acetylsalicylic acid, salicylhydroxamic acid, and benzylhydroxamic acid. The

13. Fiedler TJ, Davey CA, Fenna RE. X-ray crystal structure and characterization of halide-binding sites of human myeloperoxidase at 1.8 A resolution. The Journal of biological chemistry. 2000;275(16):11964-11971.

14. Gardas A, Sohi MK, Sutton BJ, McGregor AM, Banga JP. Purification and crystallisation of the human thyroid peroxidase expressed in insect cells is soluble at high concentrations and forms diffracting crystals. The Journal of endocrinology. 1999;160(3):R13-15. biophysics. 2018;642:1-9.

17. Godlewska M, Gora M, Buckle AM, et al. A redundant role of human thyroid peroxidase 
propeptide for cellular, enzymatic, and immunological activity. Thyroid : official journal of the American Thyroid Association. 2014;24(2):371-382.

18. Chacko S, Padlan EA, Portolano S, McLachlan SM, Rapoport B. Structural studies of human autoantibodies. Crystal structure of a thyroid peroxidase autoantibody Fab. The Journal of biological chemistry. 1996;271(21):12191-12198.

664

19. Porebski BT, Keleher S, Hollins JJ, et al. Smoothing a rugged protein folding landscape by sequence-based redesign. Scientific Reports. 2016;6:33958.

20. Pettersen EF, Goddard TD, Huang CC, et al. UCSF Chimera--a visualization system for exploratory research and analysis. J Comput Chem. 2004;25(13):1605-1612.

21. Dolinsky TJ, Nielsen JE, McCammon JA, Baker NA. PDB2PQR: an automated pipeline for the setup of Poisson-Boltzmann electrostatics calculations. Nucleic Acids Research. 2004;32(suppl_2):W665-W667.

22. Søndergaard $\mathrm{CR}$, Olsson $\mathrm{MH}$, Rostkowski M, Jensen JH. Improved treatment of ligands and coupling effects in empirical calculation and rationalization of $\mathrm{p} \mathrm{K}$ a values. Journal of chemical theory and computation. 2011;7(7):2284-2295.

23. Jorgensen WL, Chandrasekhar J, Madura JD, Impey RW, Klein ML. Comparison of simple potential functions for simulating liquid water. The Journal of chemical physics. 1983;79(2):926-935.

24. Joung IS, Cheatham III TE. Determination of alkali and halide monovalent ion parameters for use in explicitly solvated biomolecular simulations. The journal of physical chemistry $B$. 2008;112(30):9020-9041.

25. Maier JA, Martinez C, Kasavajhala K, Wickstrom L, Hauser KE, Simmerling C. ff14SB: improving the accuracy of protein side chain and backbone parameters from ff99SB. Journal

683 26. Li P, Roberts BP, Chakravorty DK, Merz Jr KM. Rational design of particle mesh Ewald compatible Lennard-Jones parameters for+ 2 metal cations in explicit solvent. Journal of 
27. Berendsen HJ, Postma Jv, van Gunsteren WF, DiNola A, Haak JR. Molecular dynamics with coupling to an external bath. The Journal of chemical physics. 1984;81(8):3684-3690.

28. Phillips JC, Braun R, Wang W, et al. Scalable molecular dynamics with NAMD. Journal of computational chemistry. 2005;26(16):1781-1802.

29. Humphrey W, Dalke A, Schulten K. VMD: visual molecular dynamics. Journal of molecular graphics. 1996;14(1):33-38.

30. McGibbon RT, Beauchamp KA, Harrigan MP, et al. MDTraj: a modern open library for the analysis of molecular dynamics trajectories. Biophysical journal. 2015;109(8):1528-1532.

32. Bresson $D$, Pugniere $M$, Roquet $F$, et al. Directed mutagenesis in region $713-720$ of human thyroperoxidase assigns 713KFPED717 residues as being involved in the B domain of the discontinuous immunodominant region recognized by human autoantibodies. The Journal of

33. Rebuffat SA, Bresson D, Nguyen B, Peraldi-Roux $\mathrm{S}$. The key residues in the immunodominant region 353-363 of human thyroid peroxidase were identified. International immunology. 2006;18(7):1091-1099.

34. Estienne V, Duthoit C, Blanchin S, et al. Analysis of a conformational B cell epitope of human thyroid peroxidase: identification of a tyrosine residue at a strategic location for immunodominance. International immunology. 2002;14(4):359-366.

35. Ramaraj T, Angel T, Dratz EA, Jesaitis AJ, Mumey B. Antigen-antibody interface properties: composition, residue interactions, and features of 53 non-redundant structures. Biochimica

710 36. Bordo D, Argos P. Evolution of protein cores. Constraints in point mutations as observed in 
globin tertiary structures. Journal of molecular biology. 1990;211(4):975-988.

37. Jiang Q-X, Wang D-N, MacKinnon R. Electron microscopic analysis of KvAP voltagedependent $\mathrm{K}+$ channels in an open conformation. Nature. 2004;430(7001):806-810.

38. Conway JF, Watts NR, Belnap DM, et al. Characterization of a Conformational Epitope on of Virology. 2003;77(11):6466-6473.

39. Wu S, Avila-Sakar A, Kim J, et al. Fabs enable single particle cryoEM studies of small proteins. Structure (London, England : 1993). 2012;20(4):582-592.

40. Gardas A, Lewartowska A, Pasieka Z, Sutton BJ, McGregor AM, Banga JP. Human Thyroid Peroxidase (TPO) Isoforms, TPO-1 and TPO-2: Analysis of Protein Expression in Graves'

41. Godlewska M, Krasuska W, Czarnocka B. Biochemical properties of thyroid peroxidase (TPO) expressed in human breast and mammary-derived cell lines. PloS one. 2018;13(3):e0193624.

42. de Carvalho DP, Lima de Souza EC, Fortunato RS, et al. Functional Consequences of Dual Endocrinology \& Metabolism. 2010;95(12):5403-5411.

43. Carvalho DP, Dupuy C. Role of the NADPH Oxidases DUOX and NOX4 in Thyroid Oxidative Stress. European thyroid journal. 2013;2(3):160-167.

44. Elisei R, Vassart G, Ludgate M. Demonstration of the existence of the alternatively spliced form of thyroid peroxidase in normal thyroid. The Journal of clinical endocrinology and metabolism. 1991;72(3):700-702.

45. Fayadat L, Niccoli-Sire P, Lanet J, Franc JL. Role of heme in intracellular trafficking of thyroperoxidase and involvement of $\mathrm{H} 2 \mathrm{O} 2$ generated at the apical surface of thyroid cells in autocatalytic covalent heme binding. The Journal of biological chemistry. 1999;274(15):10533-10538. 
46. de Vijlder JJM, Bikker H. Biochemistry and Physiology of Thyroid Peroxidase. 2000; Berlin, Heidelberg.

47. Baker JR, Arscott P, Johnson J. An analysis of the structure and antigenicity of different forms of human thyroid peroxidase. Thyroid : official journal of the American Thyroid Association. 1994;4(2):173-178.

48. McDonald DO, Pearce SH. Thyroid peroxidase forms thionamide-sensitive homodimers: relevance for immunomodulation of thyroid autoimmunity. Journal of molecular medicine (Berlin, Germany). 2009;87(10):971-980.

49. Godlewska M, Czarnocka B, Gora M. Localization of key amino acid residues in the dominant conformational epitopes on thyroid peroxidase recognized by mouse monoclonal antibodies. Autoimmunity. 2012;45(6):476-484.

50. McLachlan SM, Rapoport B. Thyroid peroxidase autoantibody epitopes revisited*. Clinical endocrinology. 2008;69(4):526-527.

51. Kass I, Hoke DE, Costa MGS, et al. Cofactor-dependent conformational heterogeneity of GAD65 and its role in autoimmunity and neurotransmitter homeostasis. Proceedings of the National Academy of Sciences. 2014;111(25):E2524-E2529.

52. Wiles AP, Shaw G, Bright J, Perczel A, Campbell ID, Barlow PN. NMR studies of a viral protein 1997;272(2):253-265.

53. Downing AK, Knott V, Werner JM, Cardy CM, Campbell ID, Handford PA. Solution structure of a pair of calcium-binding epidermal growth factor-like domains: implications for the 


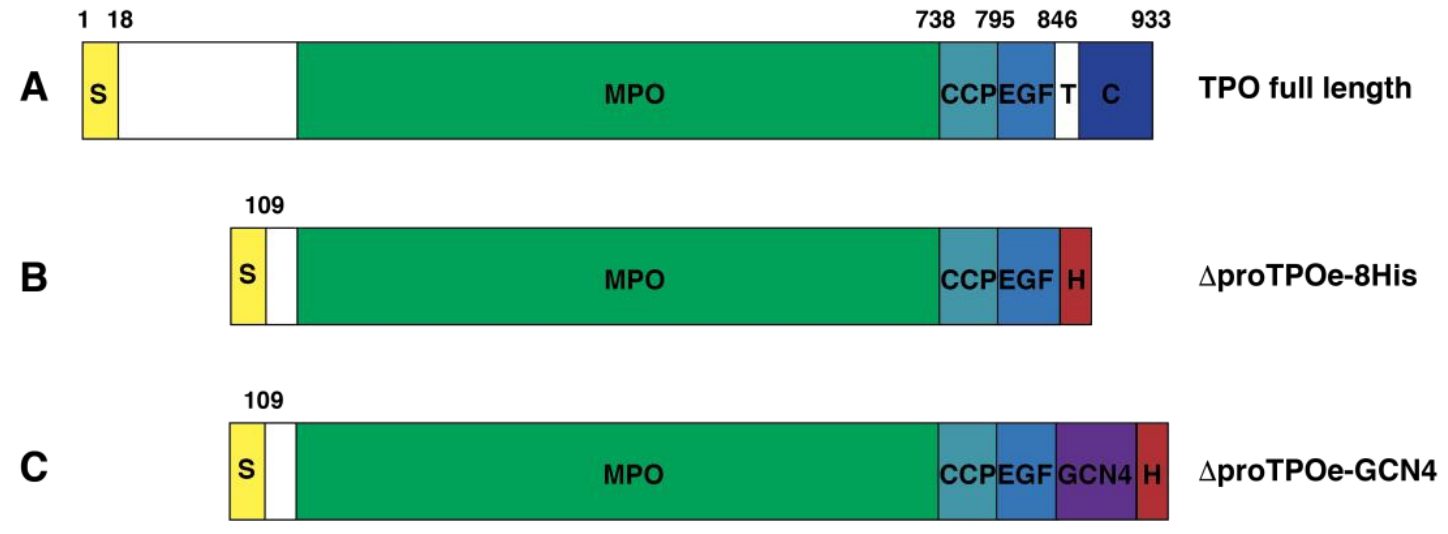

D
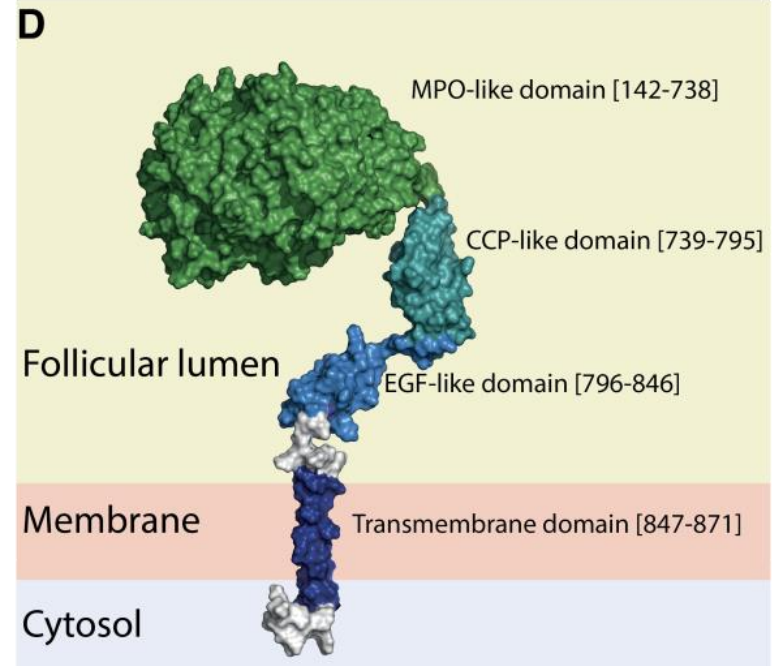

\section{MPO}

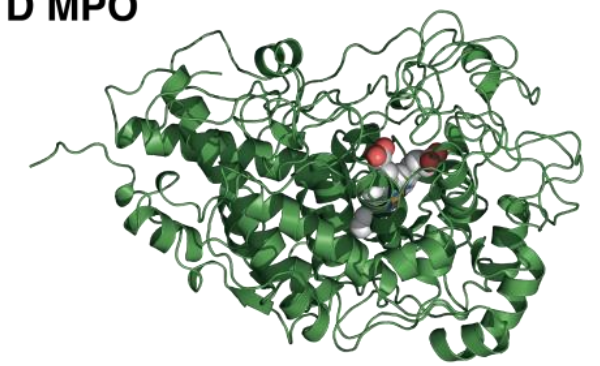

E CCP

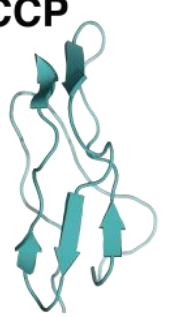

F EGF

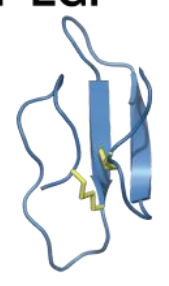

Figure 1 - Schematic showing engineered TPO constructs. (A) Full length human TPO. (B) TPO

ectodomain lacking the propeptide containing a C-terminal 8x His tag ( $\Delta$ proTPOe-8His). (C) Construct

shown in (B) fused to GCN4 ( $\triangle$ proTPOe-GCN4). S, signal peptide; MPO, MPO-like domain; CCP, CCP-

like domain; EGF, EGF-like domain; T, transmembrane span; C, cytoplasmic tail; GCN4, yeast general control protein; $\mathrm{H}, 8 \mathrm{x}$ Histidine tag. (D) Schematic showing domain organisation of a TPO monomer in its trans configuration. (E) X-ray crystal structure of human myeloperoxidase (MPO), with catalytic heme group shown as spheres (PDB ID: 1CXP) 13. (F) NMR solution structure of the Vaccinia virus complement control protein (PDB ID: 1VVD) 52. (G) NMR solution structure of a covalently linked pair of EGF-like domains from human fibrillin-1 (PDB ID: 1EMO) 53. Disulfide linkages are shown as yellow sticks. 
A

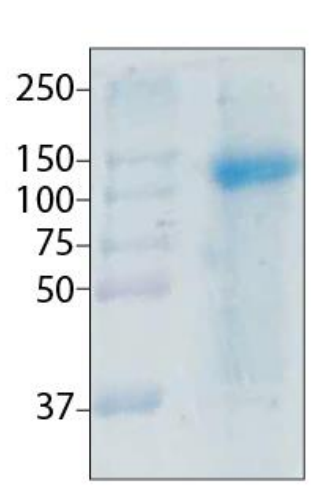

\section{B}

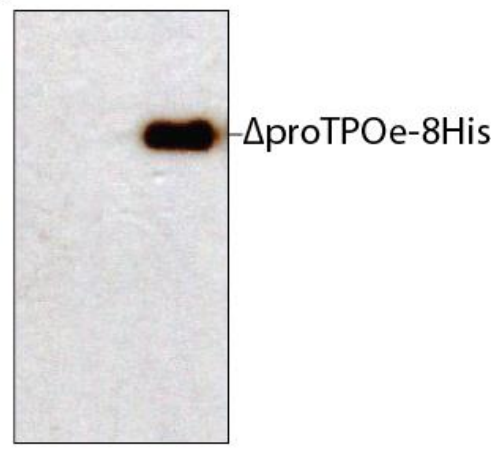

C

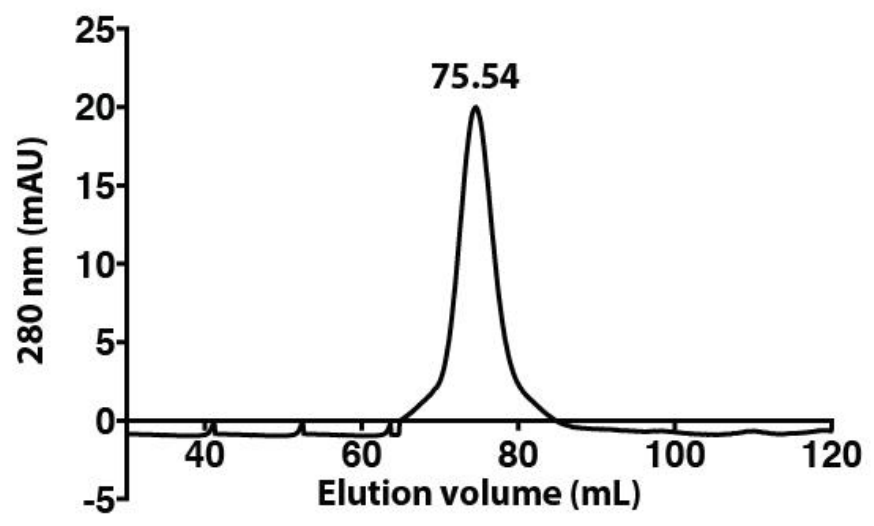

775 Figure 2 - Purification of TPO construct $\Delta$ proTPOe-8His. (A) SDS-PAGE analysis of purified 
A

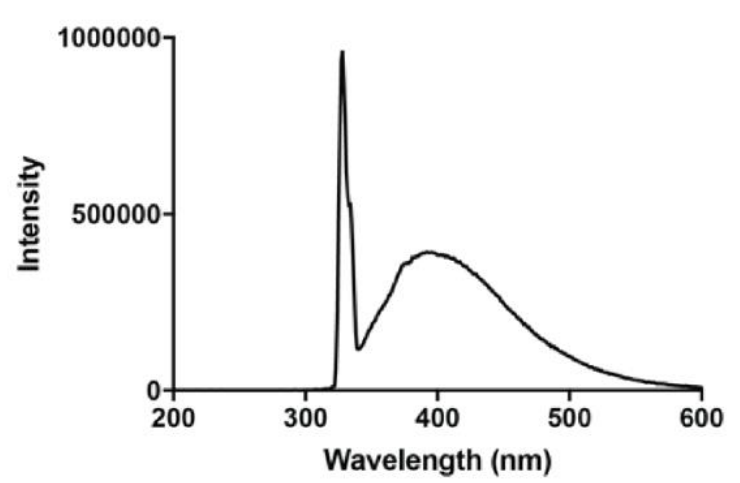

C
B

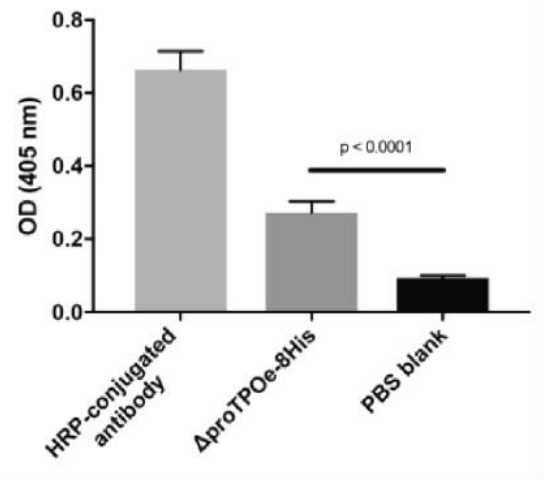

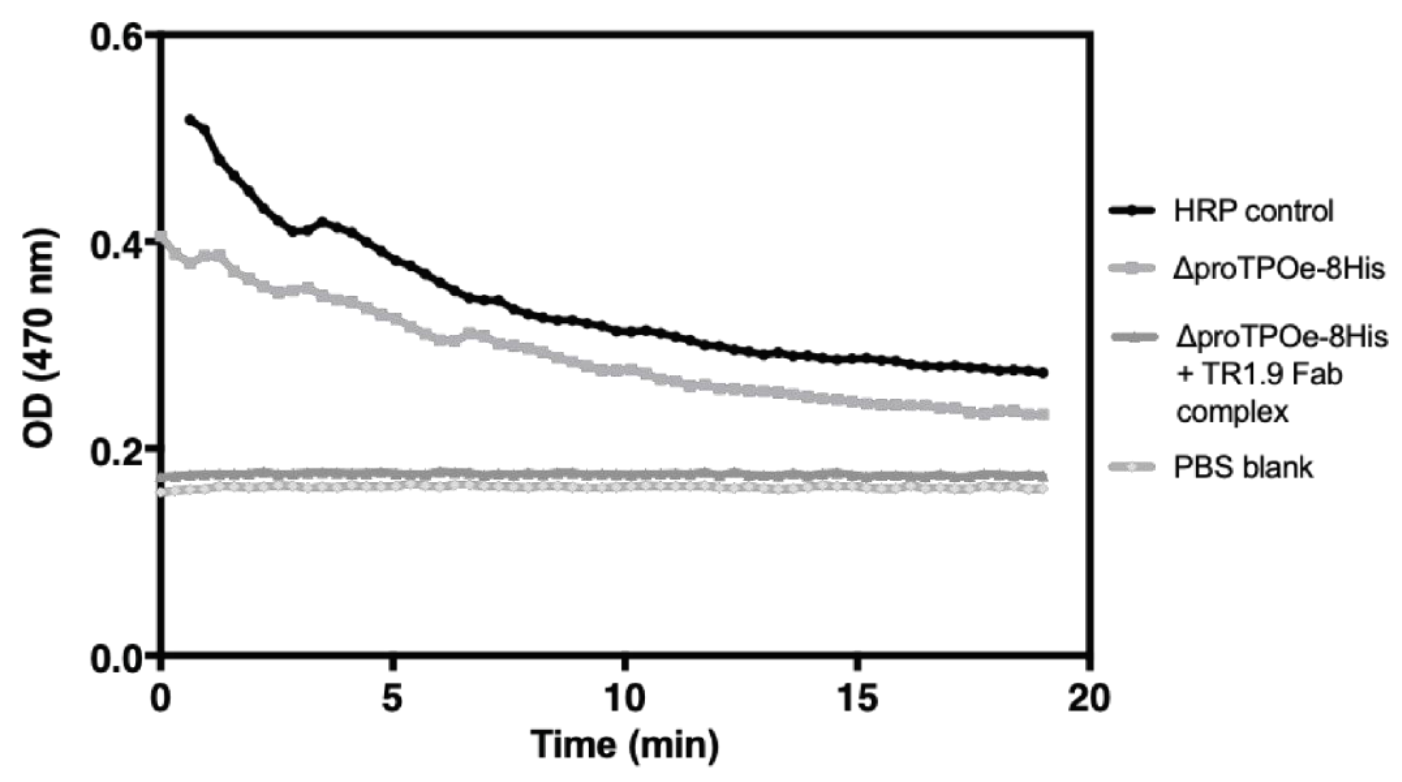

Figure 3 - Characterisation of enzyme activity. (A) Spectral scan of $\triangle$ proTPOe-GCN4. An excitation wavelength of $330 \mathrm{~nm}$ resulted in a Soret peak at $385 \mathrm{~nm}$, which is characteristic of hemoproteins. This indicates successful heme group incorporation into $\triangle$ proTPOe-GCN4. Intensity is given in arbitrary units. (B) TPO activity as measured by the guaiacol activity assay. Optical density was recorded at $405 \mathrm{~nm}$ for the three samples after 10 minutes, including an HRP positive control. $\Delta$ proTPOe-8His shows statistically significant activity indicating that it is enzymatically active. Error bars are standard deviation from the mean and statistical tests performed with a two-tailed t-test with with a $95 \%$ confidence interval. All samples were performed in quadruplicate. (C) $\triangle$ proTPOe8 His activity is prevented in the presence of TR1.9 Fab during the guaiacol assay. 


\section{A}

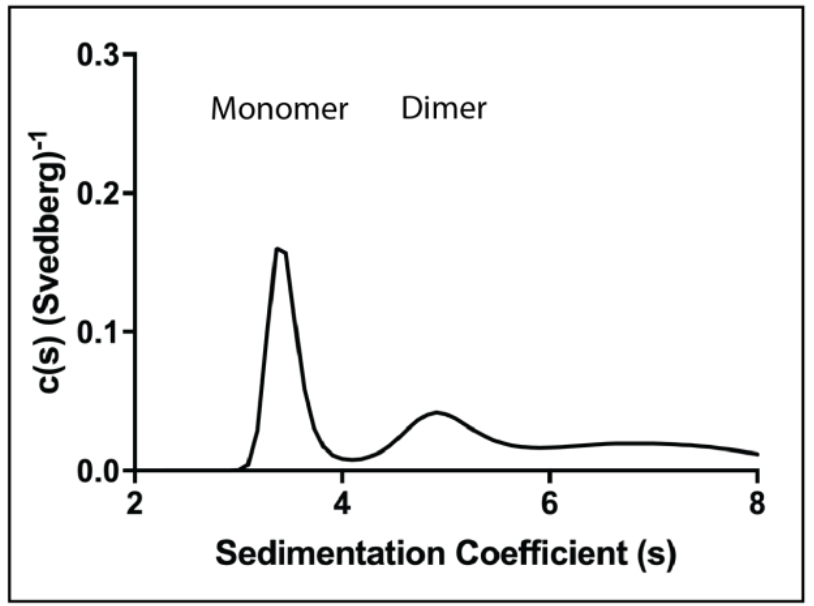

B

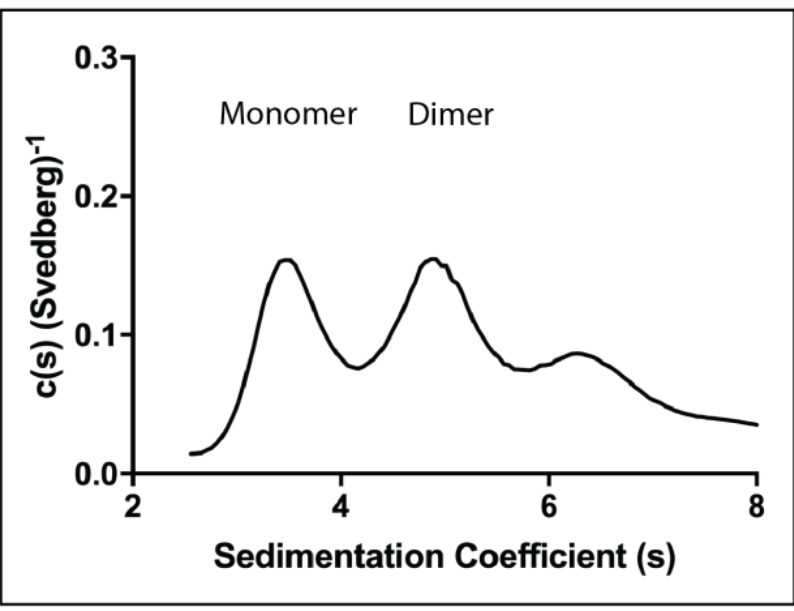

794

Figure 4 - Sedimentation distribution of $\triangle$ proTPOe-GCN4 alone and $\triangle$ proTPOe-8His alone

(A) Two distinct species are detected at a $\mathrm{sw}(20, \mathrm{w})$ of 3.6 and 5.2 respectively on the sedimentation 
A

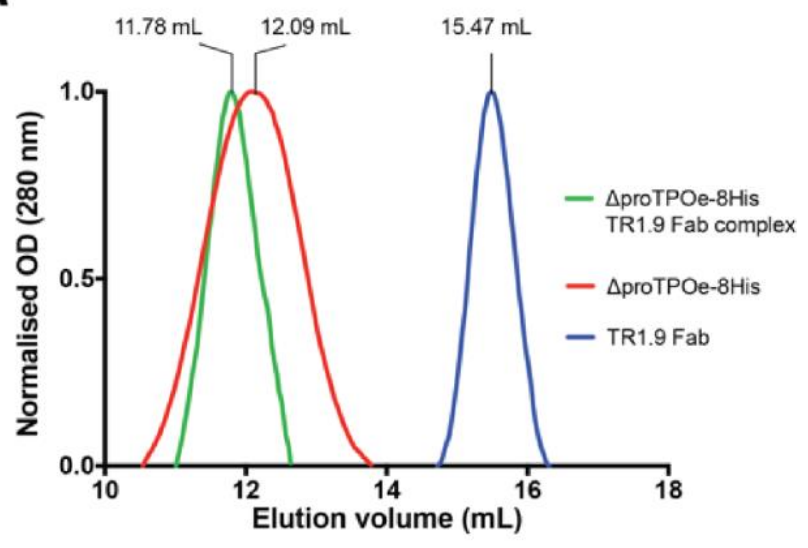

C

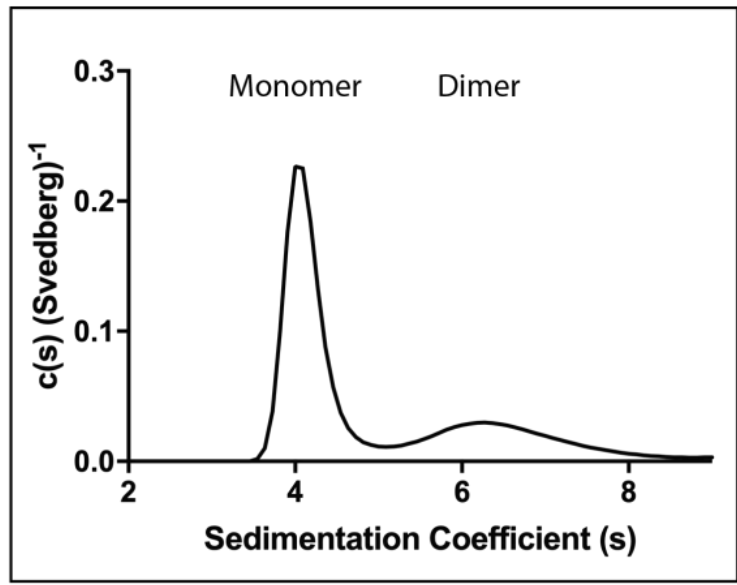

B

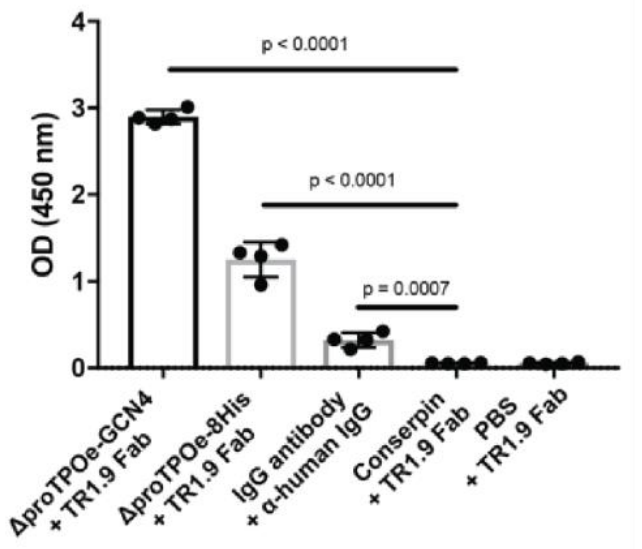

D

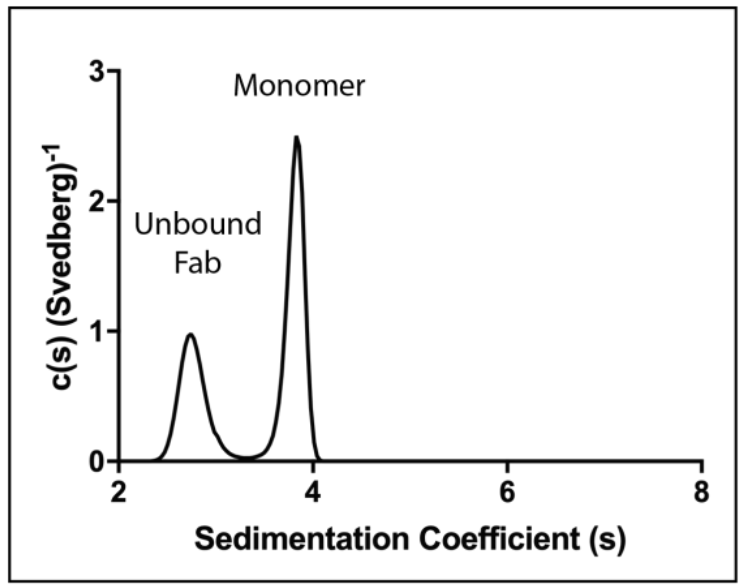

801

802 Figure 5 - TPO-TR1.9 Fab complex characterization. (A) Analytical size-exclusion chromatography

803 of the $\Delta$ proTPOe-8His-TR1.9 Fab complex. Elution profiles of $\Delta$ proTPOe-8His alone (red), $\Delta$ proTPOe-

804 8His-TR1.9 Fab complex (green) and TR1.9 Fab alone (blue). (B) ELISA results of TPO-Fab binding.

805 TR1.9 Fab shows statistically significant binding to both TPO constructs, with a $p$ value less than 0.0001 compared to a non-specific protein that does not have the required epitope (conserpin 19, negative control), as well as a PBS blank. IgG antibody and anti-human IgG was used as a positive control. Error bars are standard deviation from the mean and statistical tests performed with a twotailed t-test with a 95\% confidence interval. All samples were performed in quadruplicate. (C)

810 Sedimentation distribution of $\triangle$ proTPOe-GCN4 bound to TR1.9 Fab. Two distinct species are 811 detected at a sw(20,w) of 4.1 and 6.6 respectively. (D) Sedimentation distribution of $\Delta$ proTPOe-8His 812 bound to TR1.9 Fab. Two distinct species are detected at a sw(20,w) of 2.8 and 3.9 respectively. 
A

Trans

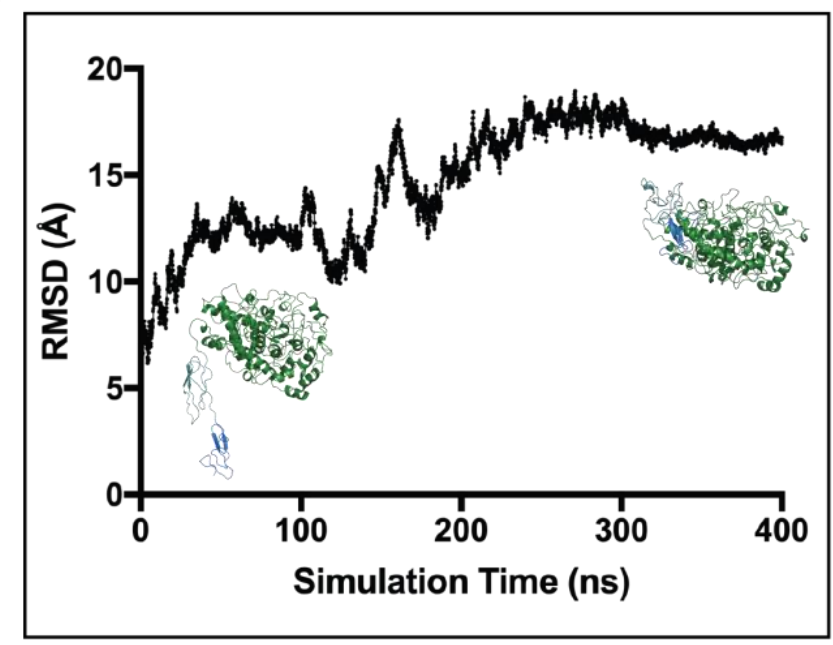

B

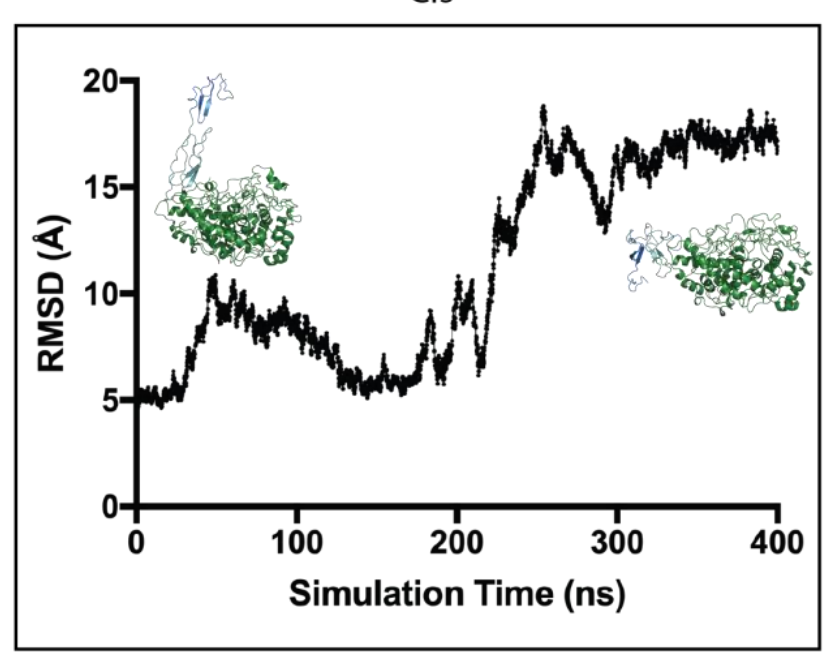

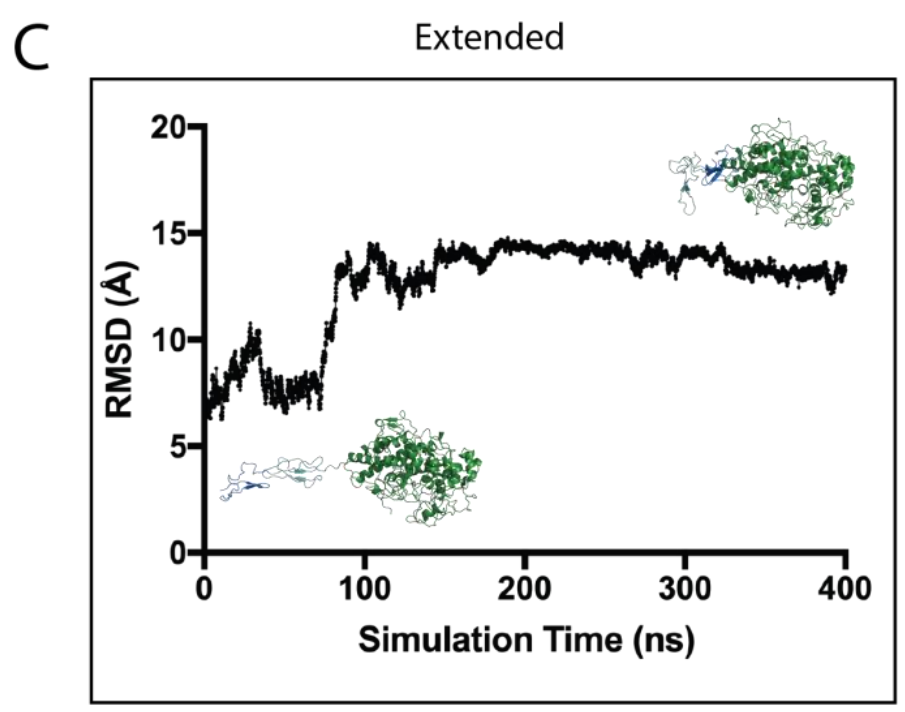

814

815 Figure 6 - Molecular dynamics simulations of a $\Delta$ proTPOe monomer. Root mean square deviations

816 (RMSD) is given as an average value per residue per 0.1ns of simulation time for the (A) trans, (B) cis

817 and $(\mathbf{C})$ extended models of $\Delta$ proTPOe. Within each panel is a model representation of a starting

818 structure of the particular form of TPO on the left, with a model taken from the plateau of the MD

819 run on the right-hand side. The MPO-like domain, CCP-like domain and EGF-like domain are coloured

820 in forest green, light teal and marine blue respectively (as in Figure 1). 
A

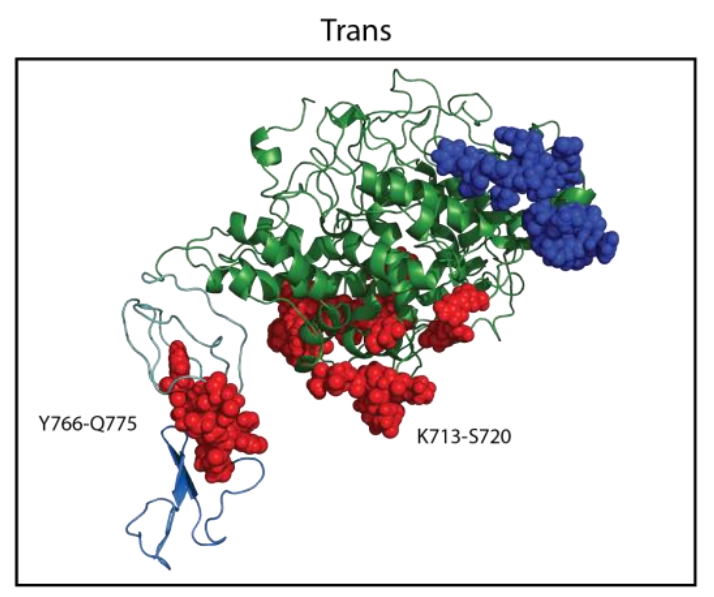

B

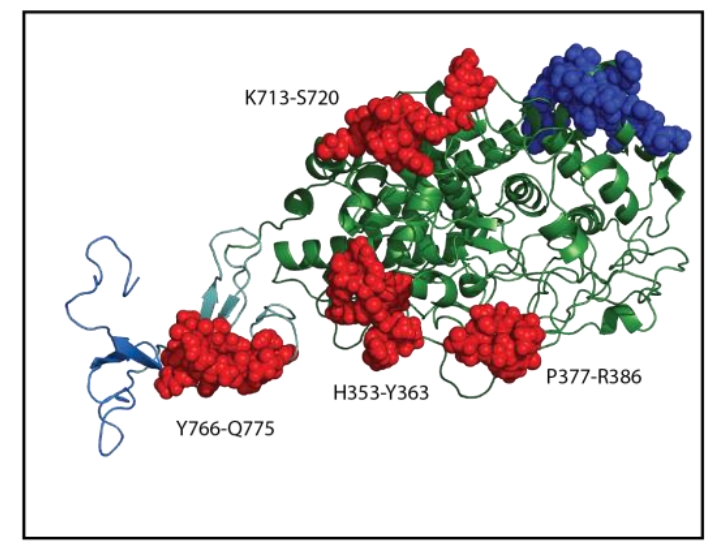

C Extended

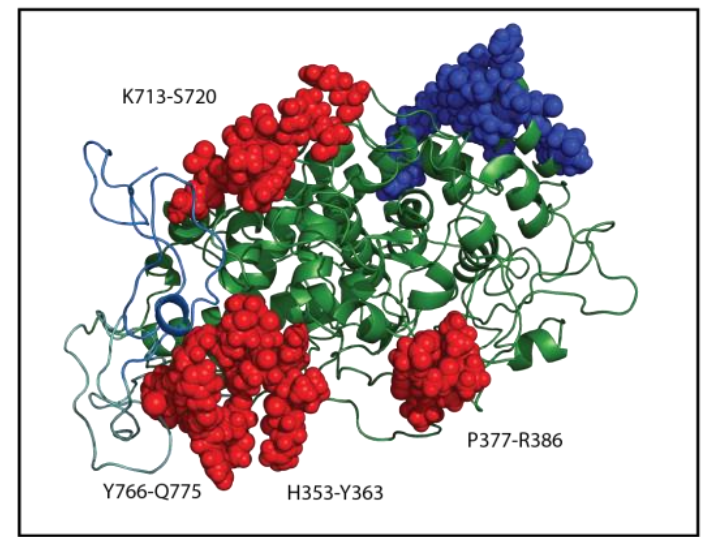

821

822 Figure 7 - IDRs in the context of the MD simulations. A representative structure taken from the MD simulations at equilibrium for each of the (A) trans, (B) cis and (C) extended forms of the $\Delta$ proTPOe monomer. IDR-A residues are highlighted by red spheres, and IDR-B residues by blue spheres. The MPO-like domain, CCP-like domain and EGF-like domain are coloured in forest green, light teal and marine blue respectively (as in Figure 1). (A) The IDR-A epitopes of K713-S720 and Y766-Q775 are 28

$827 \AA$ apart from each other in this selected frame from the trans MD simulation. (B) In the cis model, Y766-Q775 is $21 \AA$ from the H353-Y363 epitope and $40 \AA$ away from the P377-R386 epitopes. (C) In this representation of the extended model during the MD simulation, all four labelled epitopes of

830 IDR-A are no more than $43 \AA$ away from each other. A comparison showing these structures compared with the starting TPO models is shown in Figure S6. 
bioRxiv preprint doi: https://doi.org/10.1101/2019.12.15.876789; this version posted December 16, 2019. The copyright holder for this preprint (which was not certified by peer review) is the author/funder, who has granted bioRxiv a license to display the preprint in perpetuity. It is made available under aCC-BY-NC-ND 4.0 International license.

832

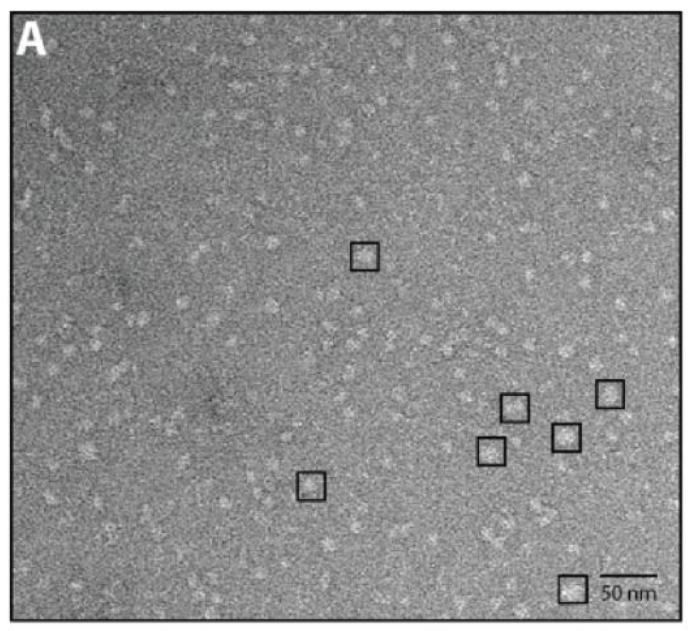

\section{C}

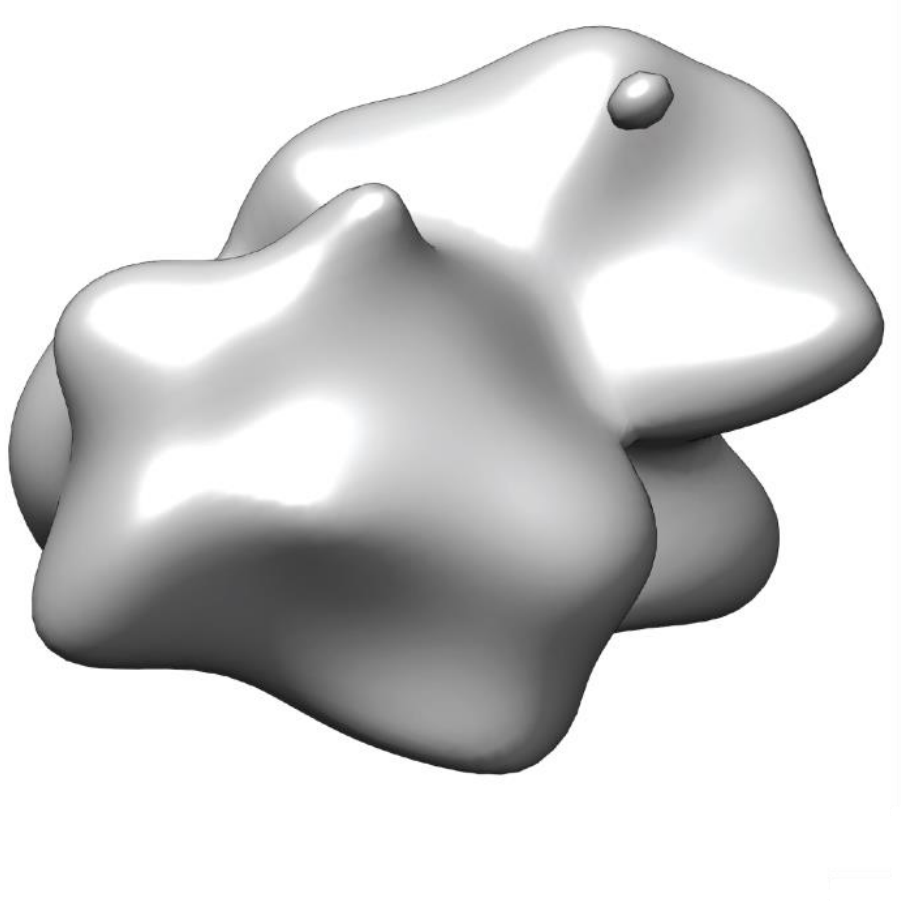

833

834 Figure 8 - Electron micrograph of $\Delta$ proTPOe-8His in complex with TR1.9 Fab. (A) Representative micrograph of the $\Delta$ proTPOe-8His/TR1.9 complex collected using a FEI Tecnai Spirit T12 TEM in lowdose conditions. (B) 2D class averages generated from the single particles picked in (A) and used for initial 3D model generation. (C) 3D reconstruction of the EM volume.

838

839 
bioRxiv preprint doi: https://doi.org/10.1101/2019.12.15.876789; this version posted December 16, 2019. The copyright holder for this preprint (which was not certified by peer review) is the author/funder, who has granted bioRxiv a license to display the preprint in perpetuity. It is made available under aCC-BY-NC-ND 4.0 International license.
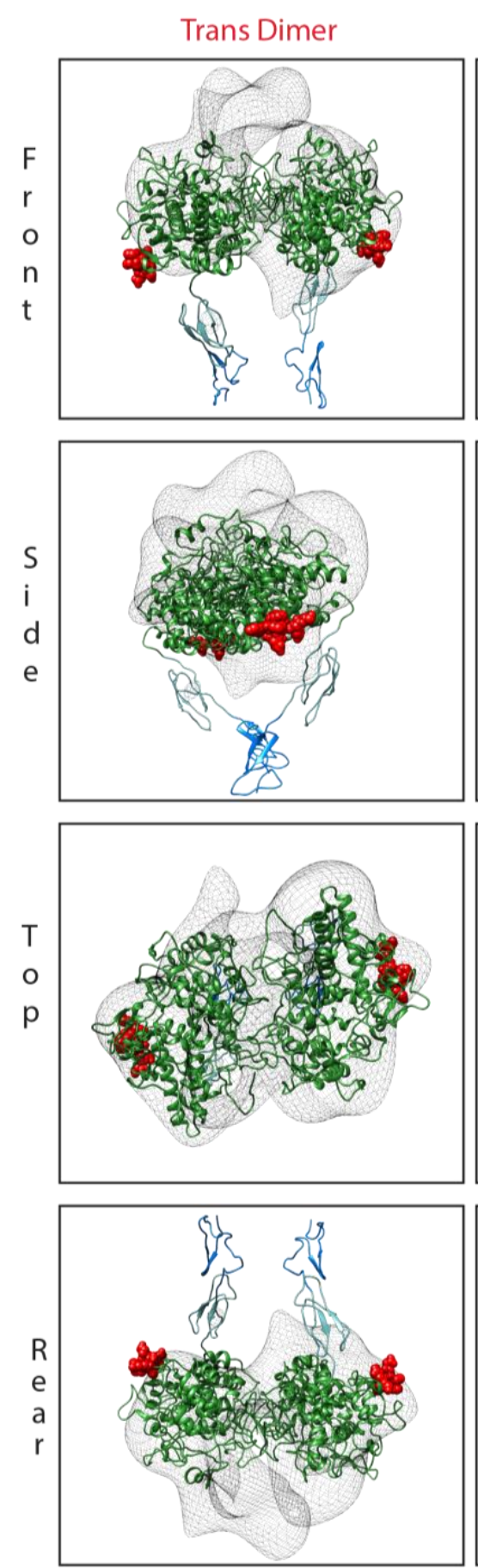

\section{Trans Monomer + TR1.9}
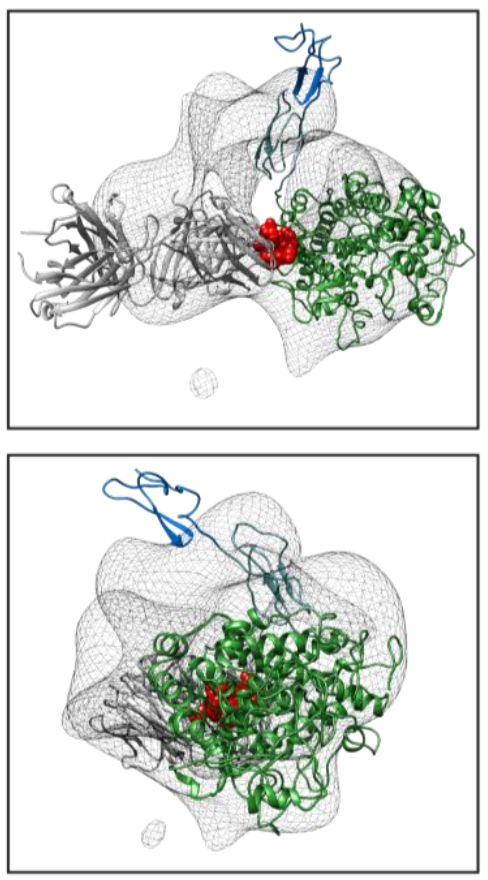

Curled Monomer + TR1.9 Fab
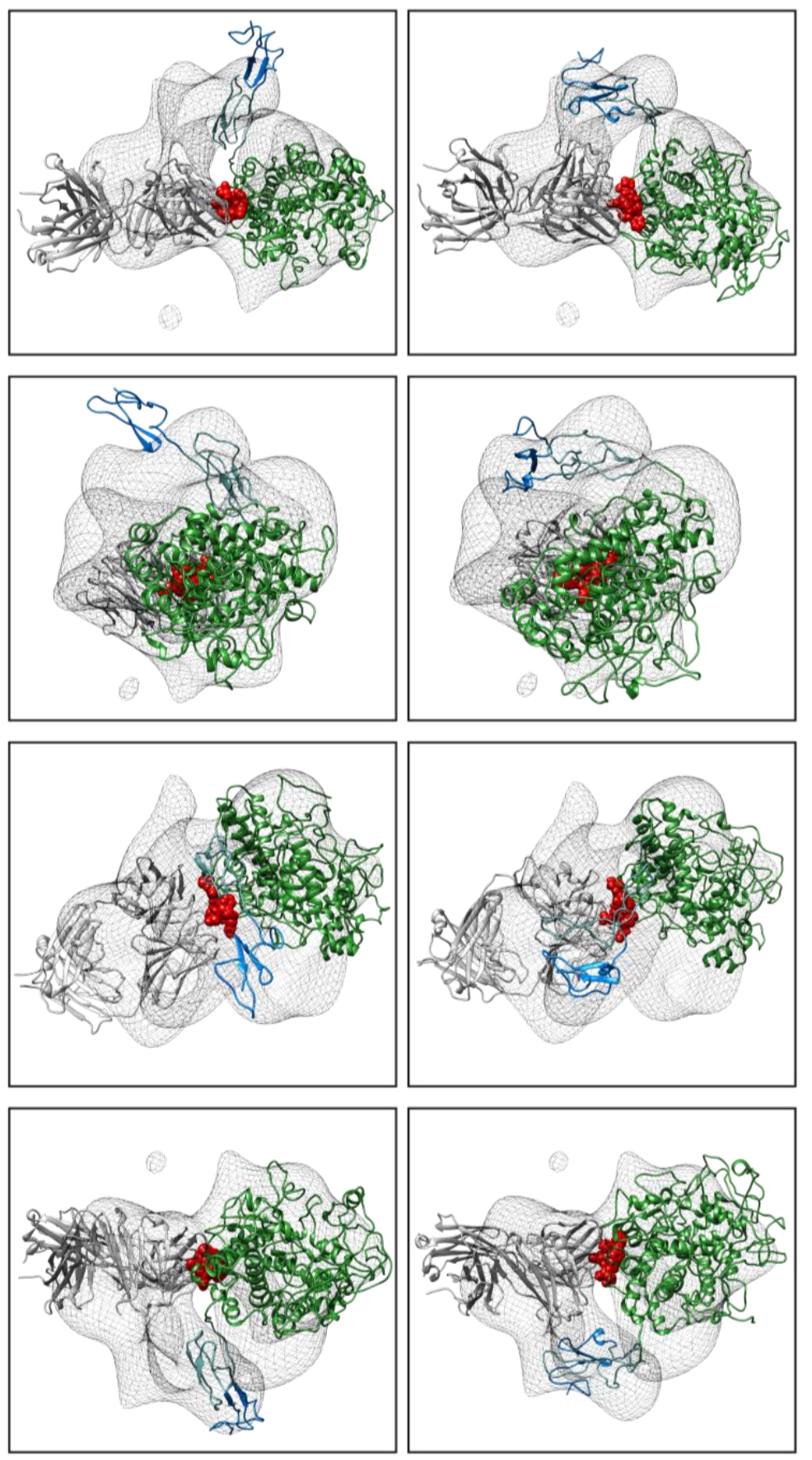

842 Figure 9 - Construction of a 3D model of the $\Delta$ proTPOe-8His-TR1.9 complex via negative stain EM.

843 3D reconstruction of the $\Delta$ proTPOe-TR1.9 Fab complex. $\Delta$ proTPOe trans dimer alone, $\Delta$ proTPOe

844 trans monomer with docked TR1.9 Fab, and monomer from MD simulations with docked TR1.9 Fab

845 were fitted into the EM envelope and are marked in their respective columns. The MPO-like domain,

846 CCP-like domain and EGF-like domain are coloured in forest green, light teal and marine blue

847 respectively (as in Figure 1). The previously published TR1.9 epitope (K713-S720) is indicated by red 
bioRxiv preprint doi: https://doi.org/10.1101/2019.12.15.876789; this version posted December $16,2019$. The copyright holder for this preprint (which was not certified by peer review) is the author/funder, who has granted bioRxiv a license to display the preprint in perpetuity. It is made available under aCC-BY-NC-ND 4.0 International license.

848 spheres. Rows indicate orientation: Top and rear represent $a+90^{\circ}$ and $+270^{\circ}$ rotation respectively

849 in the $\mathrm{y}$ axis with respect to the Front representation, while Side indicates a $-90^{\circ}$ rotation in the $\mathrm{x}$ 850 axis with respect to the Front representation.

851 